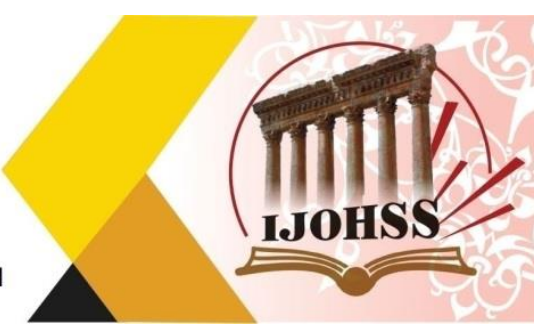

\title{
واقع جهود أكاديمية الملكة رانيا ومساعيها لتحقيق الجودة والارتقاء بمستوى التعليم
}

\author{
بسمة خلف عيادة الحسبان
}

مديرة مدرسة فاطمة بنت الخطاب الثانوية للبنات

وزارة التربية والتعليم

عمّان - الاردن

البريد الاككتروني: basmaalhusban@gmail.com

الملخص

هدفت الدراسة التعرف على دور أكاديمية الملكة رانيا في دعم التطوير المهني للمعلم والقيادة التربوية دعما

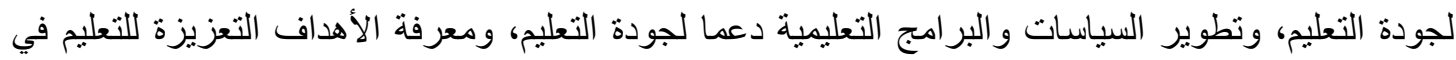

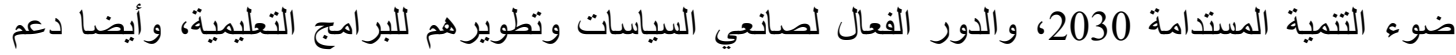

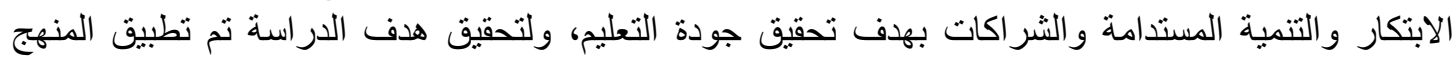

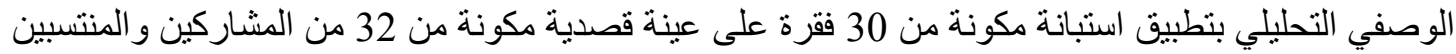

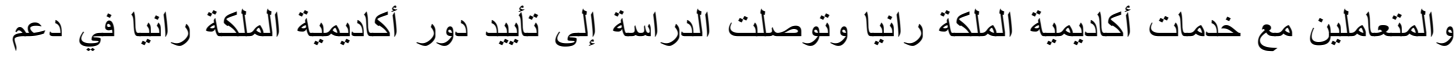

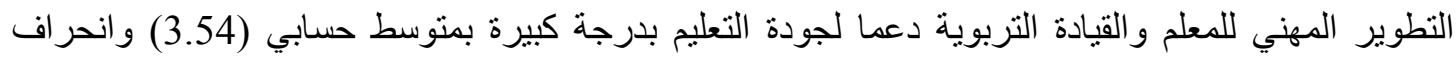

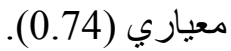
و أكدت الأغلبية على دور أكاديمية الملكة رانيا في تطوير السياسات والبرامج التعليمية دعما لجودة التعليم.

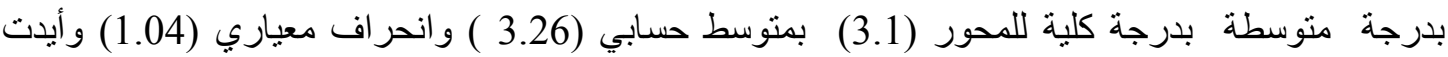

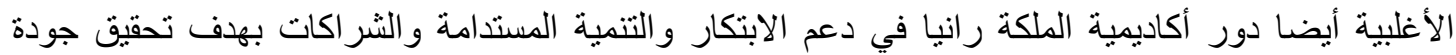
التعليم بدرجة كبيرة بدرجة كلية للمحور (2.8) بمتوسط حسابي للاستجابات (3.64) و وانحر اف معياري (0.73)

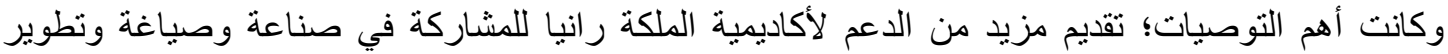

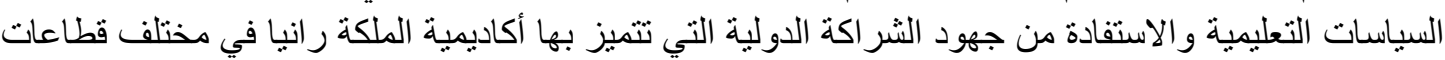

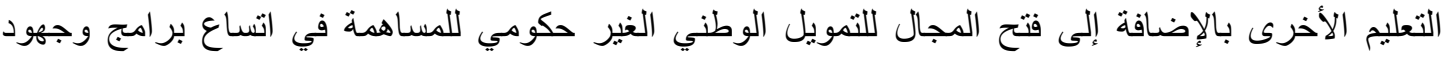
أكاديمية الملكة رانيا.

الكلمات الافتتاحية: أكاديمية الملكة رانيا، جودة التعليم، التتمية المستدامة، منصة إدار الك. 


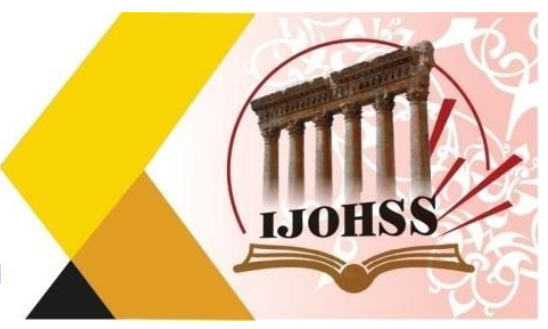

\title{
The Reality of Queen Rania Academy's Efforts and Endeavors to Achieve Quality and Raise The Level of Education
}

\author{
Basmah Khalaf Aeadah Al-Husban \\ Manager of Fatima Bint Al-Khattab Secondary School for Girls \\ The Ministry of Education \\ Ammaan- Jordan \\ Email: basmaalhusban@gmail.com
}

\begin{abstract}
The study aimed to identify the role of the Queen Rania Academy in supporting the professional development of teachers and educational leadership in support of the quality of education, the development of educational policies and programs in support of the quality of education, and knowledge of the objectives of promoting education in the light of sustainable development 2030, and the effective role of policy makers and their development of educational programs, as well as supporting innovation and sustainable development And partnerships in order to achieve the quality of education, and to achieve the goal of the study, the descriptive analytical approach was applied by applying a questionnaire consisting of 30 paragraphs to an intentional sample of 32 participants, affiliates and dealers with the services of the Queen Rania Academy. In support of the quality of education to a large extent with an arithmetic mean (3.54) and a standard deviation (0.74).

The majority emphasized the role of the Queen Rania Academy in developing educational policies and programs in support of quality education. An average score for the axis (3.1) with an arithmetic mean (3.26) and a standard deviation (1.04) The majority also supported the role of the Queen Rania Academy in supporting innovation, sustainable development and partnerships in order to achieve the quality of education to a large degree with a total score for the axis (2.8) with an arithmetic mean of responses (3.64) and a deviation normative (0.73) and the most important recommendations were; Providing more support to the Queen Rania Academy to participate in the formulation, formulation and development of educational policies and to benefit from the international partnership efforts that characterize the Queen Rania Academy in various other education sectors, in addition to opening the way for national non-governmental funding to contribute to the expansion of the Queen Rania Academy's programs and efforts.
\end{abstract}

Keywords: Queen Rania Academy, quality of education, sustainable development, Edraak platform. 


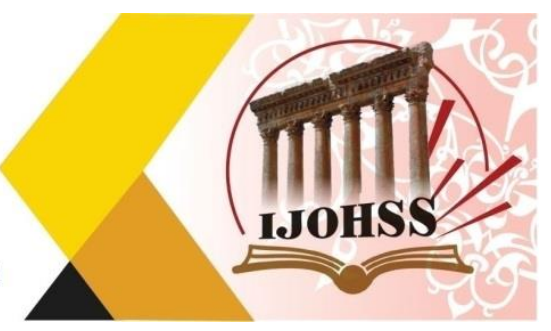

مقدمة

إيماءا بالمعرفة المنهجية وتطوير الجودة التعليمية من خلال عملية التصنيف المتكامل، التى تساعد فى تحديد

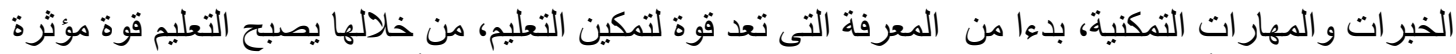

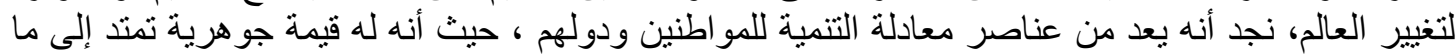

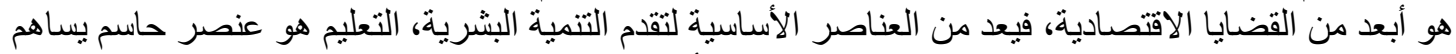

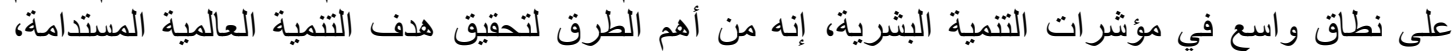

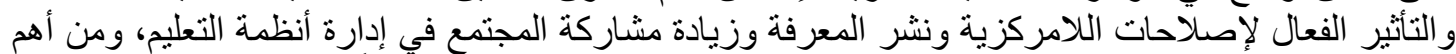

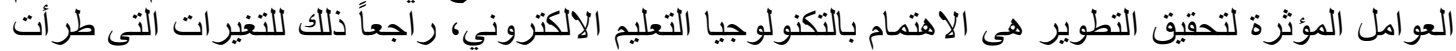

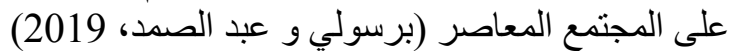

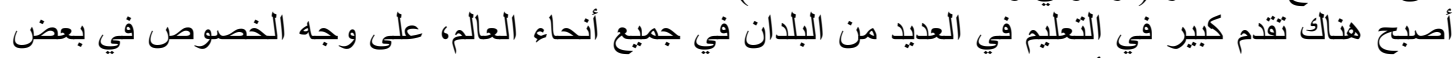

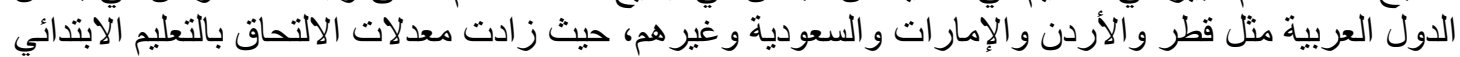

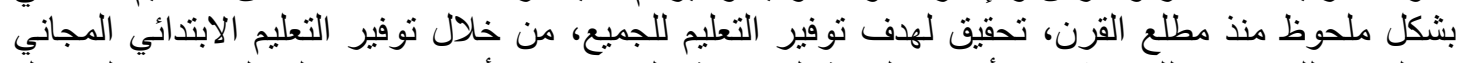

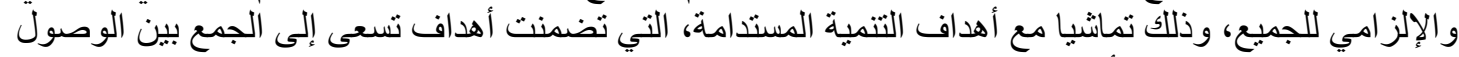

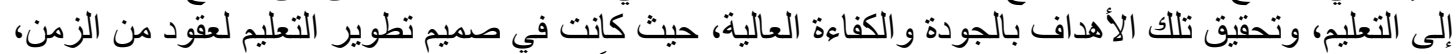

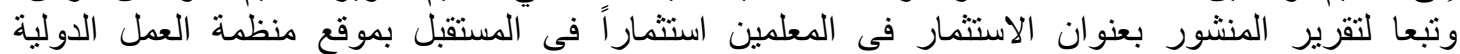

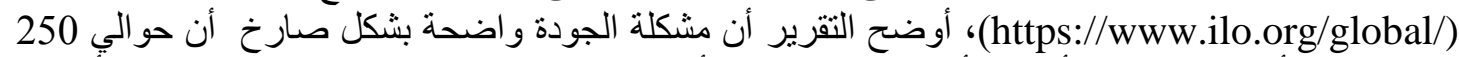

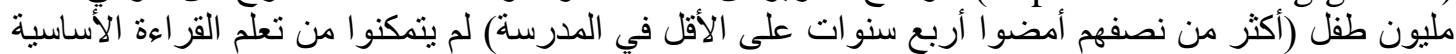

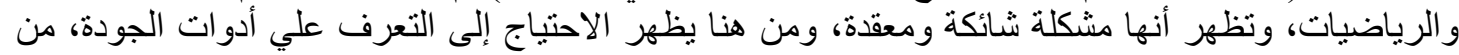

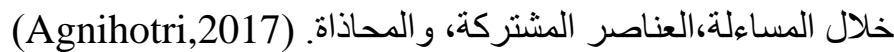

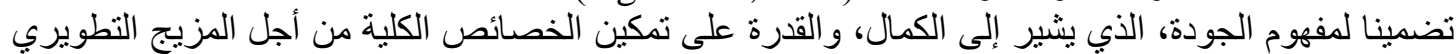

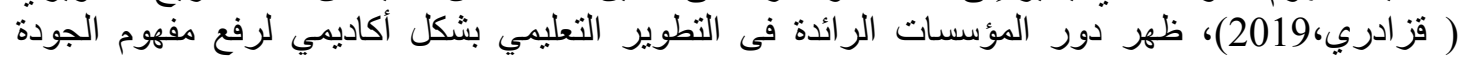

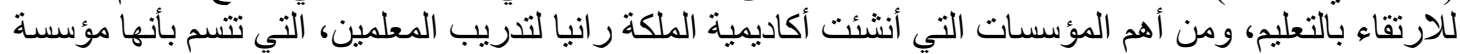

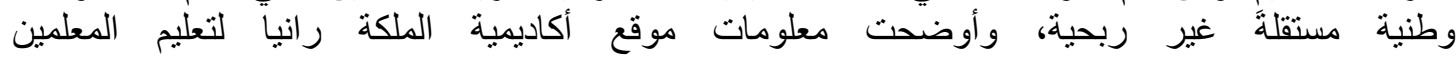
(https://qrta.edu.jo/)

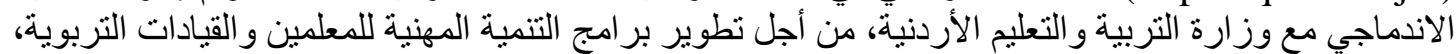

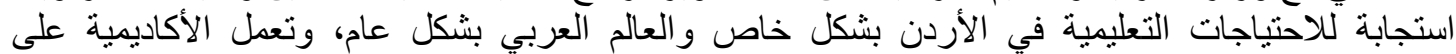

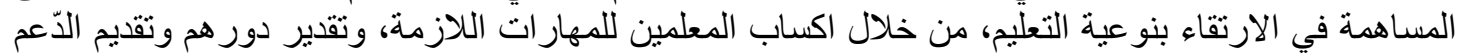

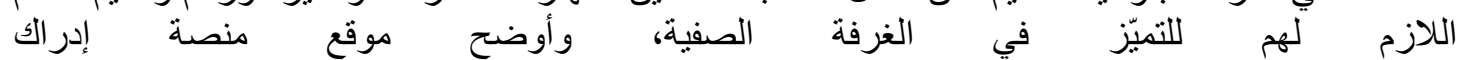
(https://www.edraak.org/partner/qrta/)

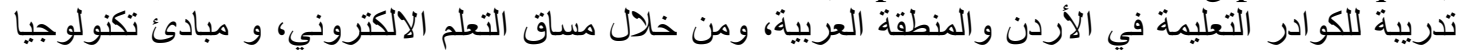

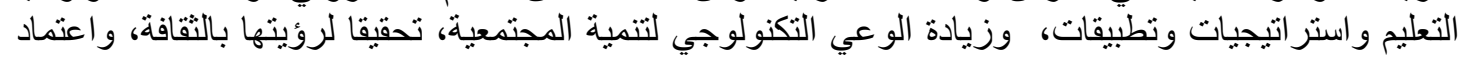

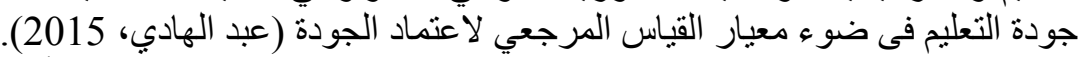

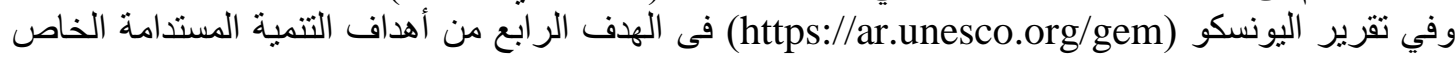

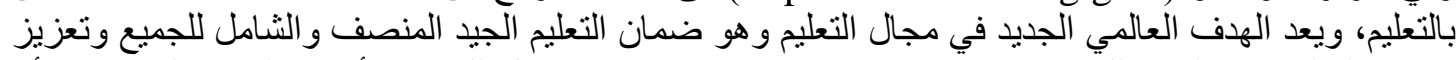

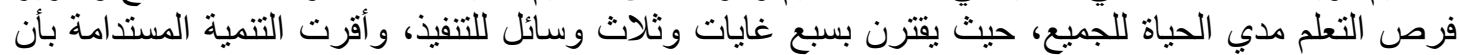

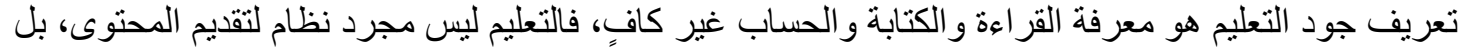

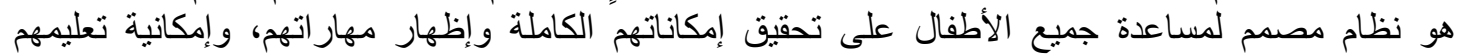

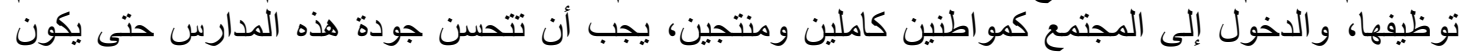

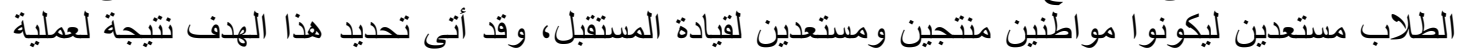

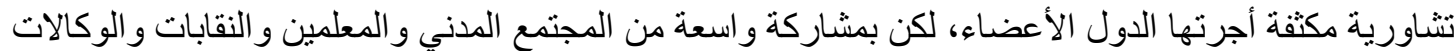

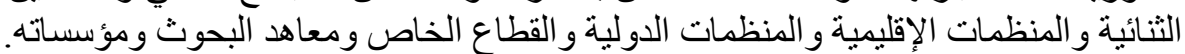




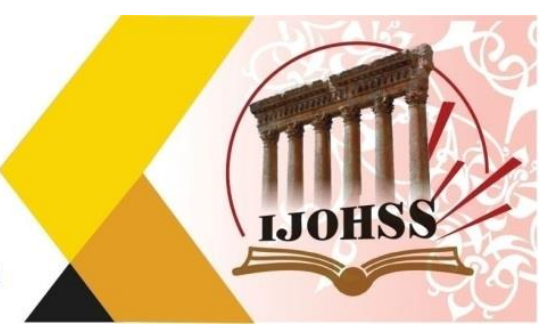

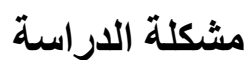

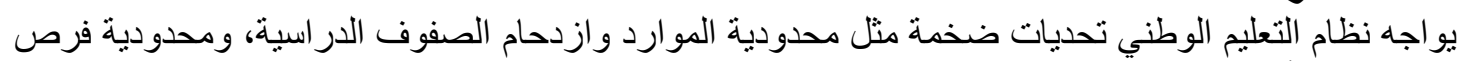

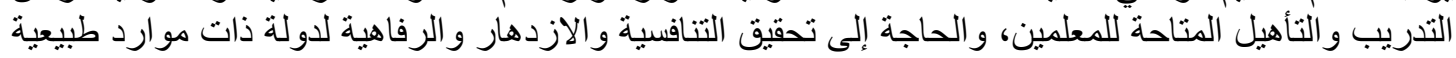

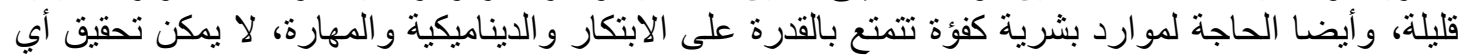

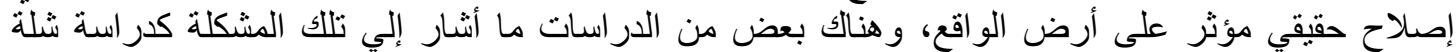

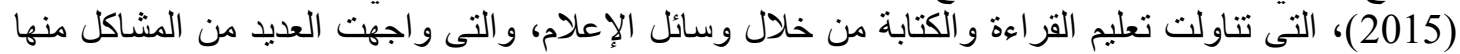

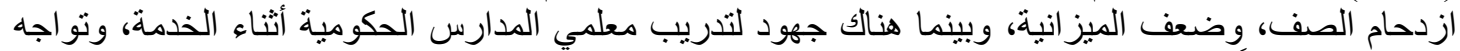

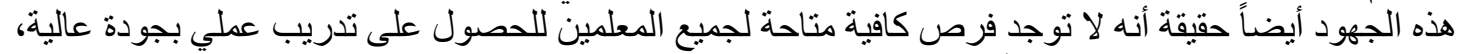

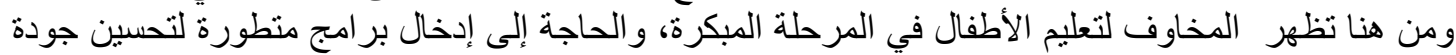

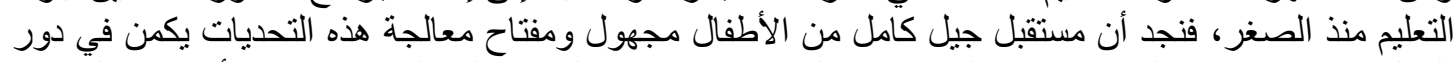

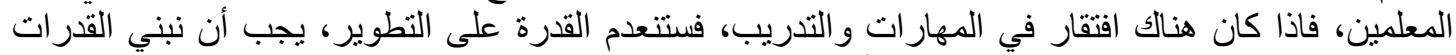

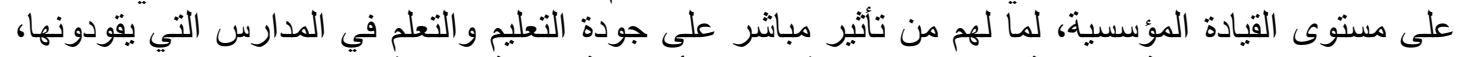

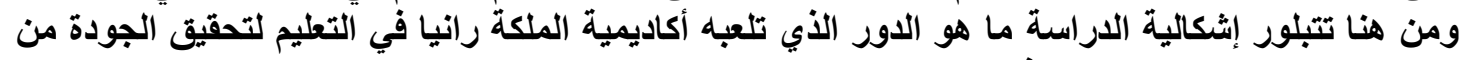

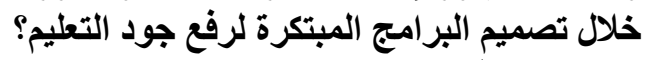
تساؤ لات الدر استة

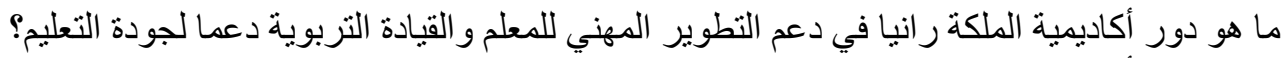

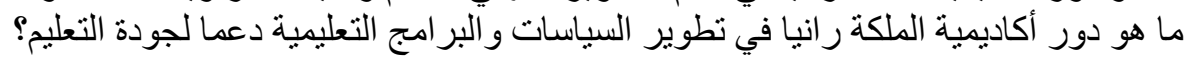

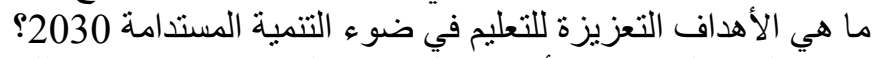

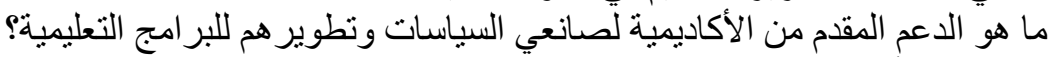

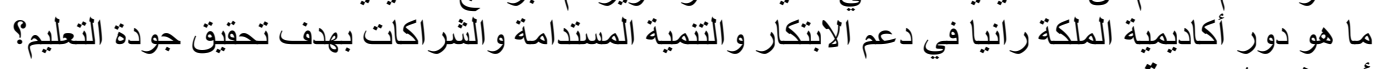
أهداف الار استة التعرف على دور أكاديمية الملكة رانيا في دعم التطوير المهني للمعلم و القيادة التربوية دعما لجودئ التيادة التعليم.

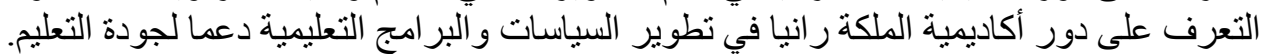

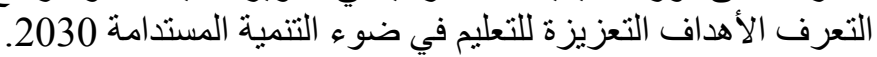

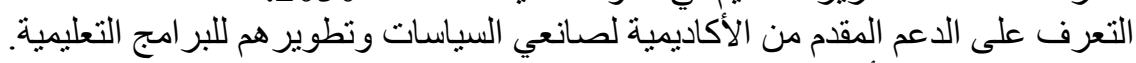

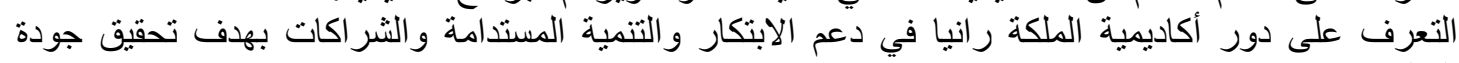
ترجع أهمية الدراسة في الحاجة لتحقيق النمو و التنمية المستدامين للأجيال الحالية والمقبلة في العالم العربي

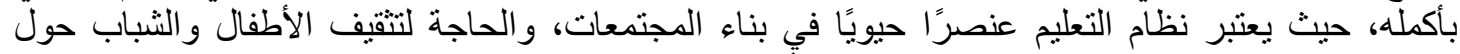

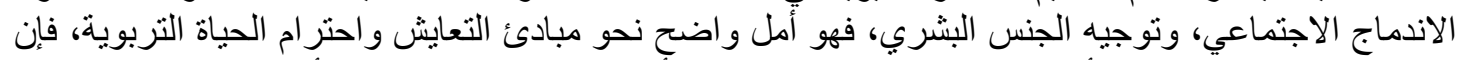

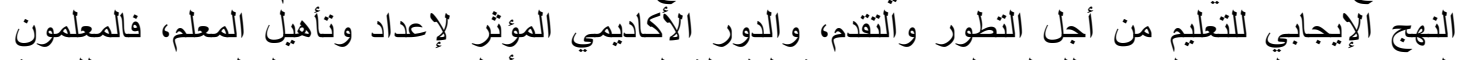

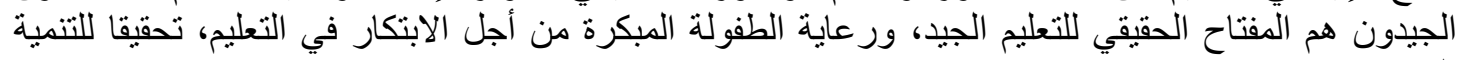

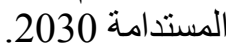

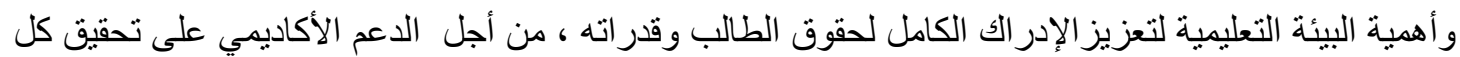

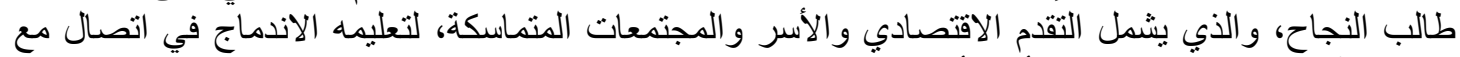

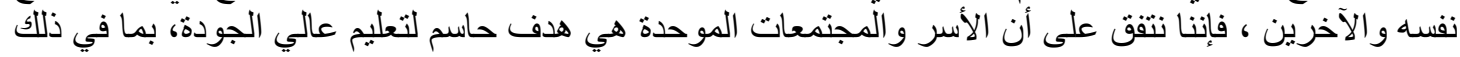

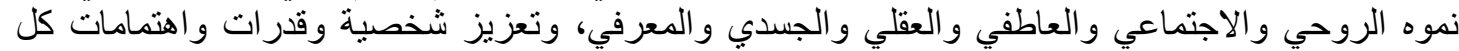

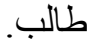
أو لاًا: الأهمية النظرية

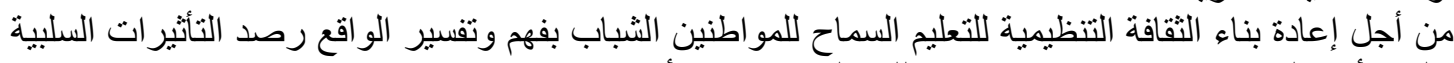
على الأمن النفسي و الاجتماعي و انعكاس ذللك على مستوى الأداء. 


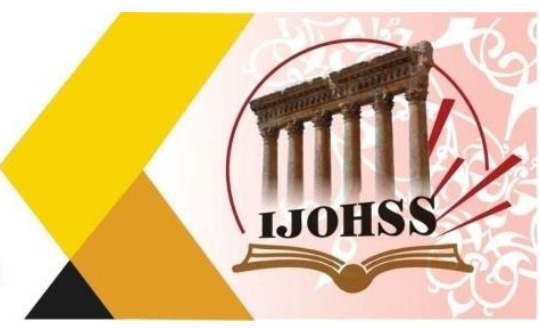

رصد وجهات نظر الممارسين حول كيف يمكن التطوير من جودة التعليم

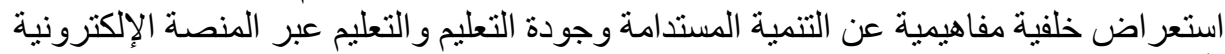

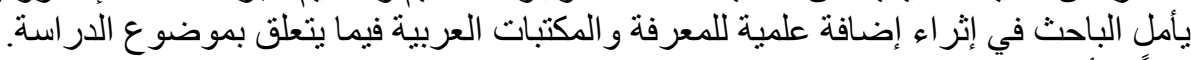
ثانياً: الأهمية التطبيقية في التراه قد تسهم نتائج الدراسة الحالية الألية بالكثف وتحقيق قراءة نقدية للعالم، تجعل من المكن للتعليم نحو الالتزام و العمل

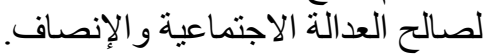

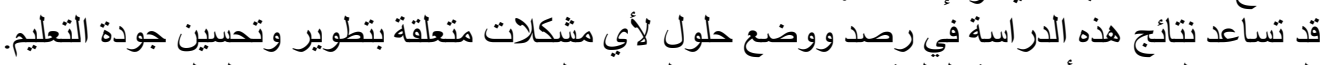

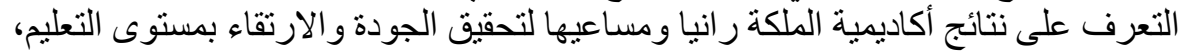

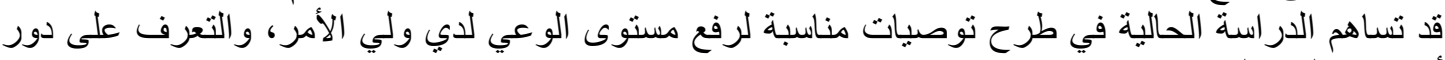

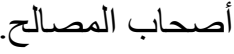
حدود البحث

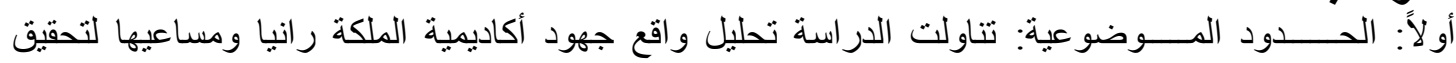

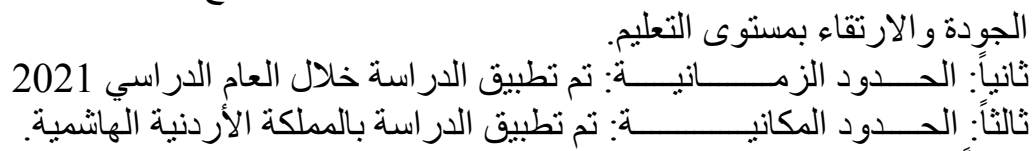

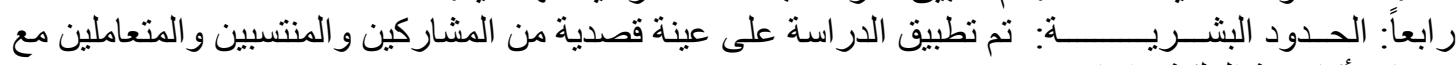
خدمات أكاديمية الملكة رانيا.

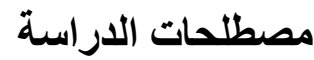
جودة التعليم: التعليم الجيد بالمعنى السليم من الناحية التربوية والتنموية ويثقف الطالب في أن يصبح عضوًا

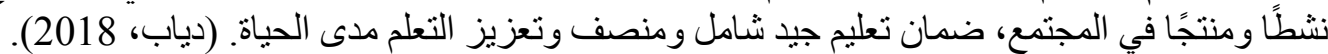

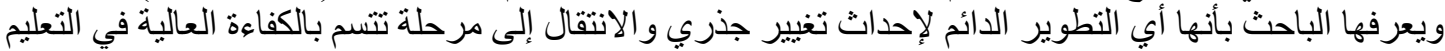

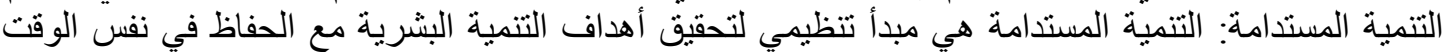

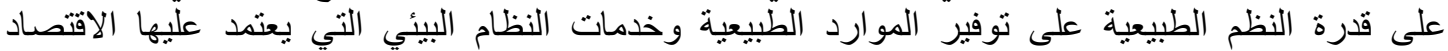

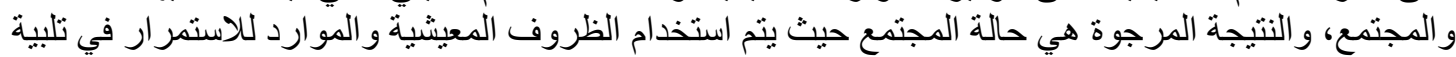

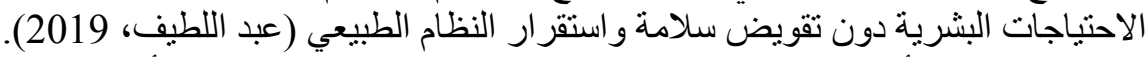

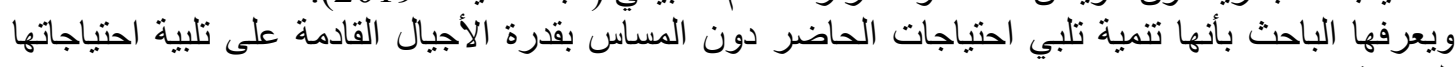

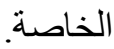
المعوقات: وهي كل موقف أو حالة تعرقل تحقيق الأهداف التربوية بكفاية وفاعلية، وتحتاج إلى دارسةٍ علميةٍ لتحديد أسبابها، ومعالجتها؛ لسد الفجوة بين مستوى الإنجاز المتوقع والإنهان الإنجاز (محمد، 2018).

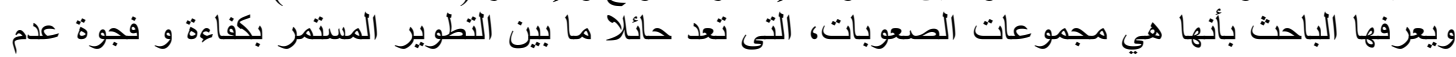
الوصول للتنمية المستدامة. منصة إدراك: إدراك هي منصة إلكترونية عربية للمساقات الجماعية مفتوحة المصادرة، تم تأسيس إدراك الك والك

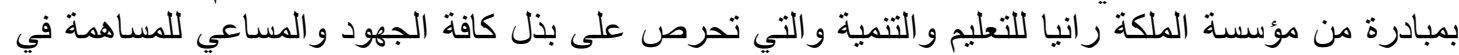

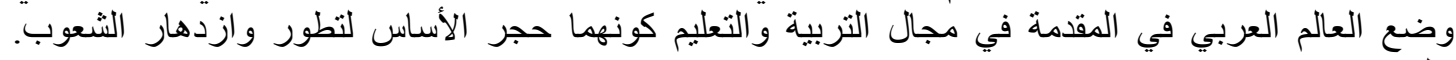

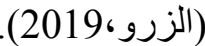
ويعرفها الباحث بأنها هي منصة إلكترونية للتعليم عن بعد، أي مجموعة تفاعلات تعليمية يكون فيها المعلم

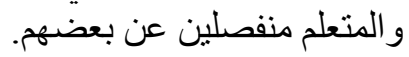




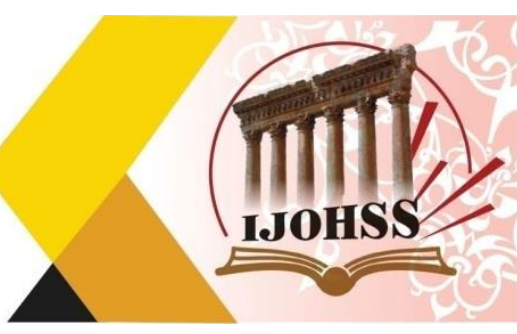

الإطار النظري والاراسات السابقة

الاراسات السابقة

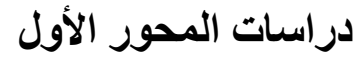

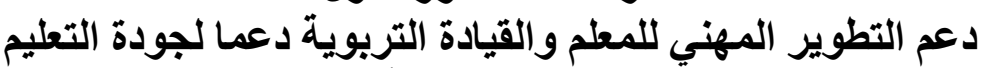

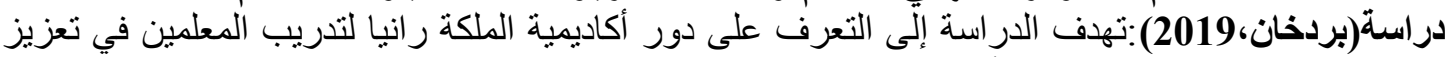

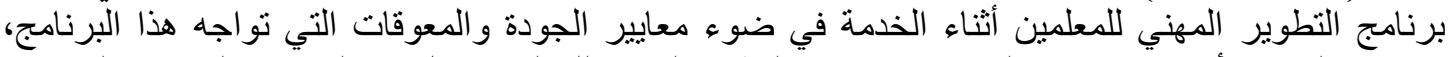

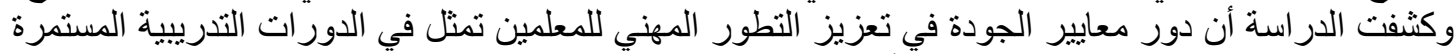

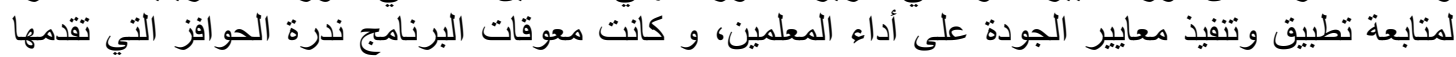

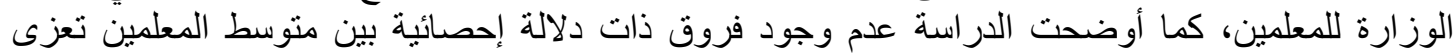

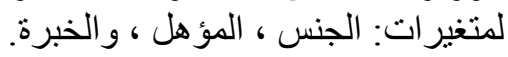

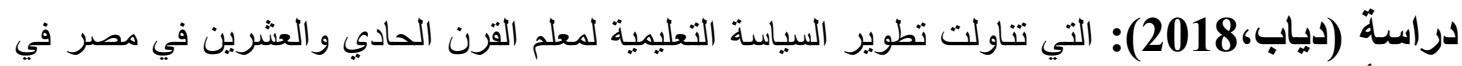

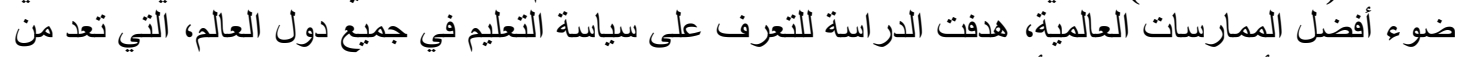

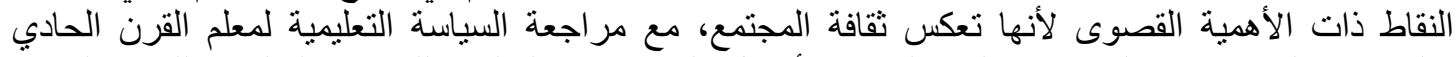

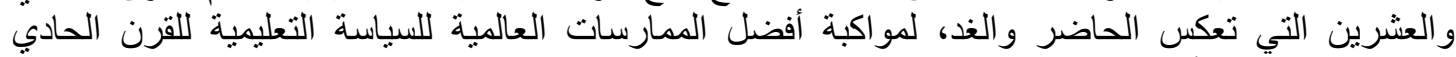

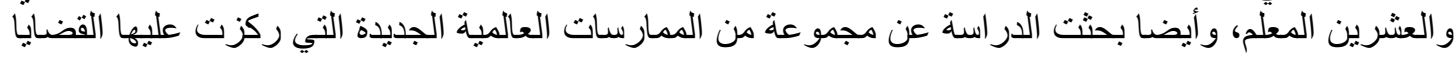

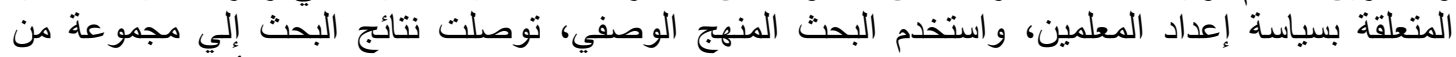

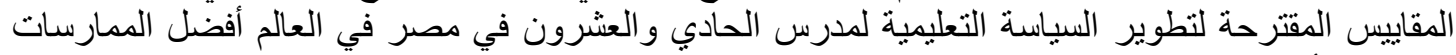
الخفيفة، وأوصت الدراسة بتحديد المسارات المهنية وتحقيق الاستقلال الذاني بين المهنيين العين العاملين في مجال المنظومة التعليمية. دراسة (أبو ربيع ،2015): هدفت هذه الدراسة إلى معرفة وعي مديري المستوى بـأهمية تكنولوجيا التعليم

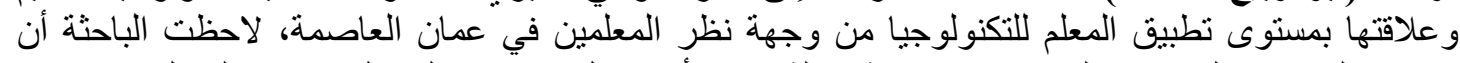

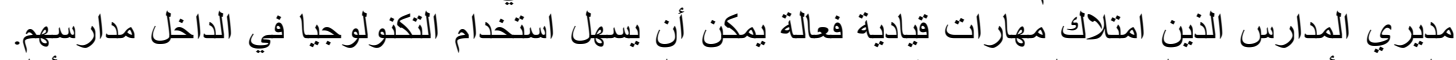

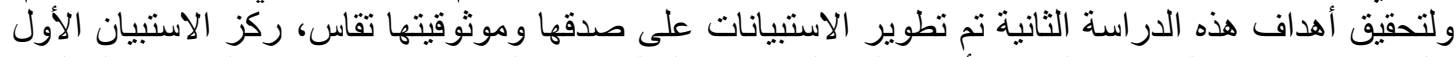

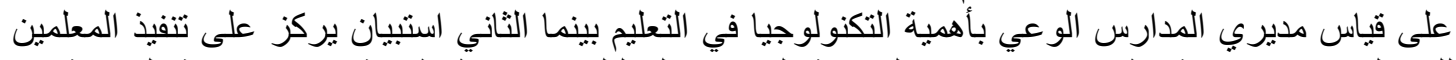

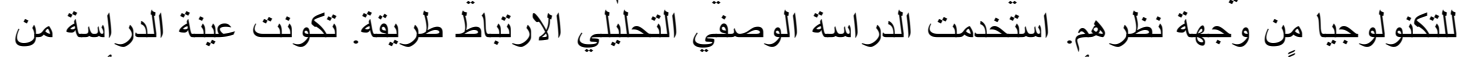

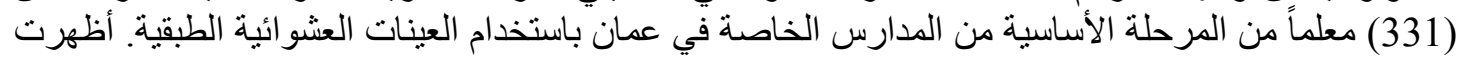

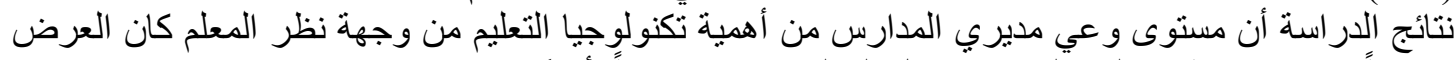

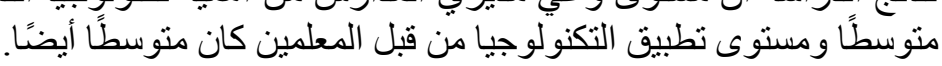

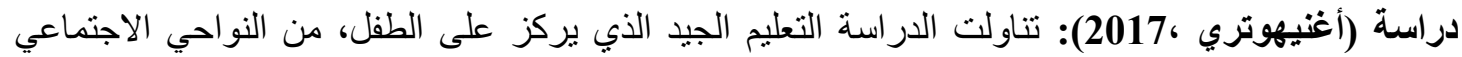

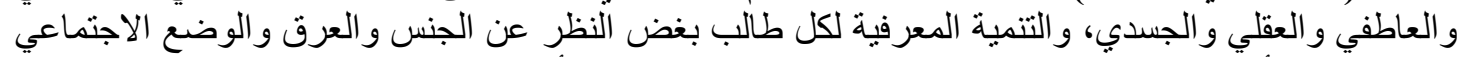

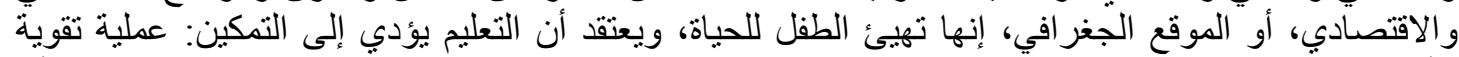

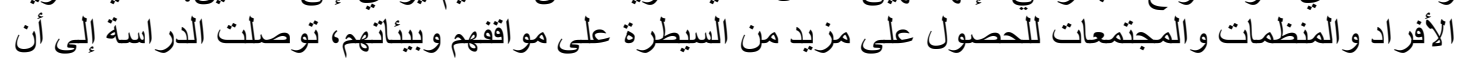

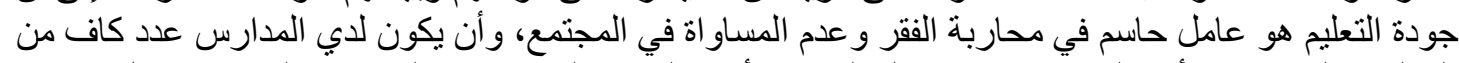

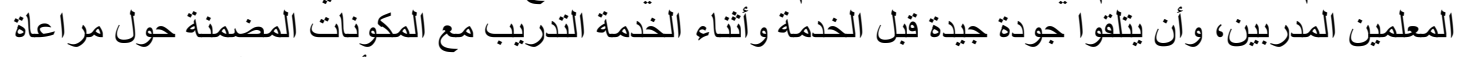

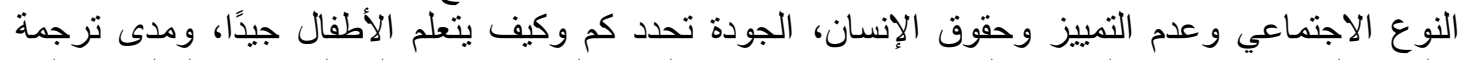

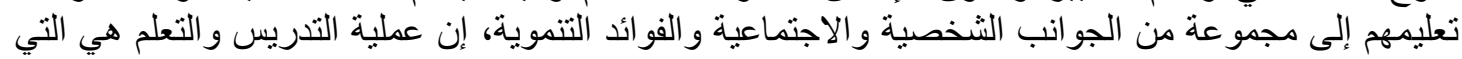

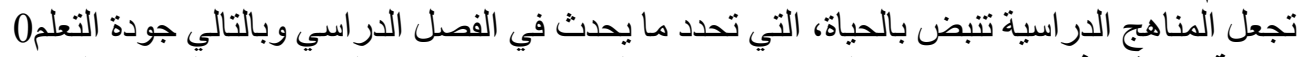

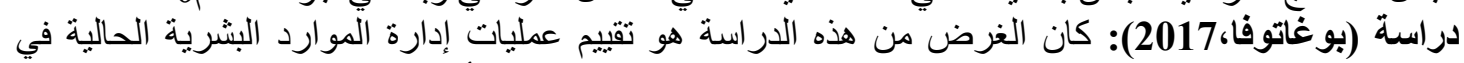

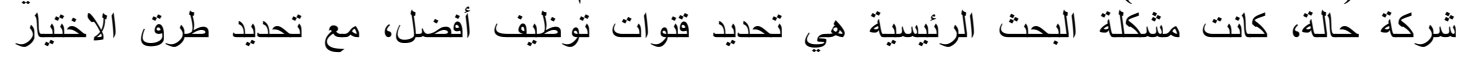

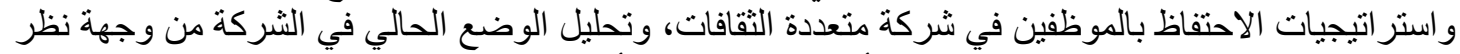

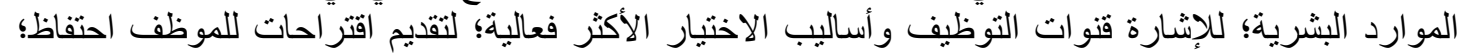




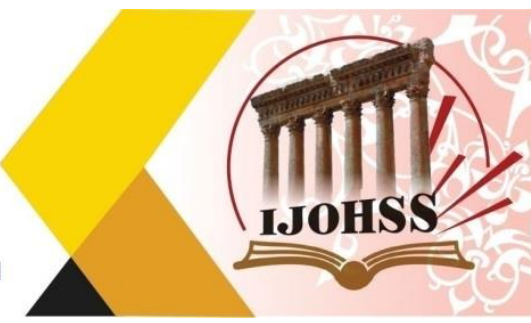

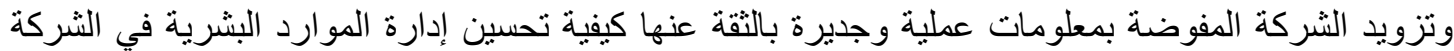

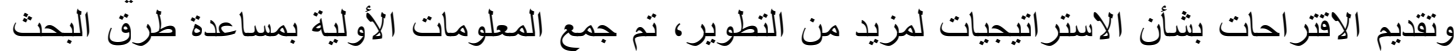

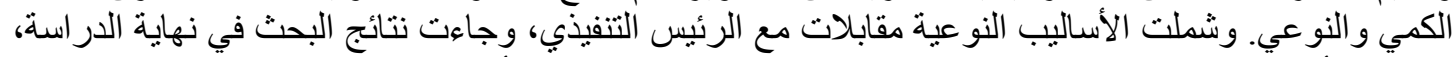

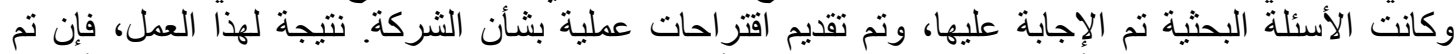

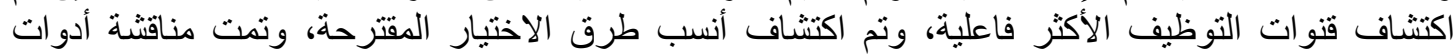
الاحتفاظ الكافية.

$$
\text { دراسـات المحور الثاني }
$$

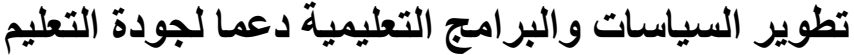

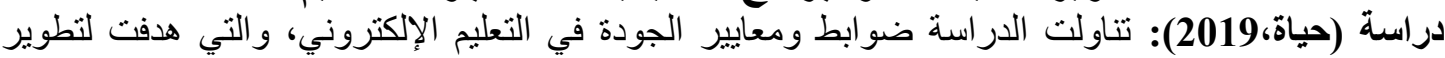

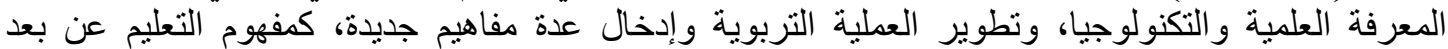

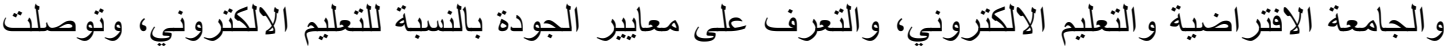

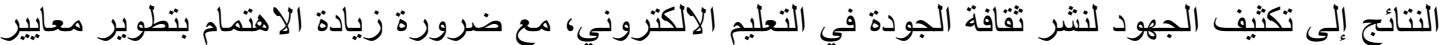

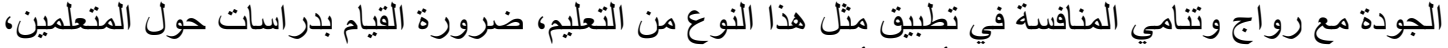

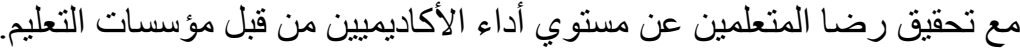

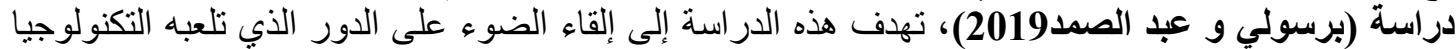

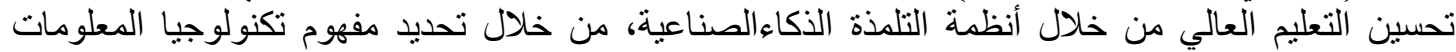

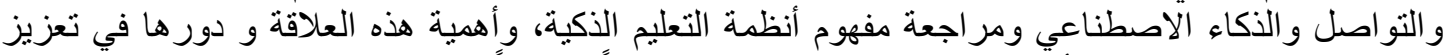

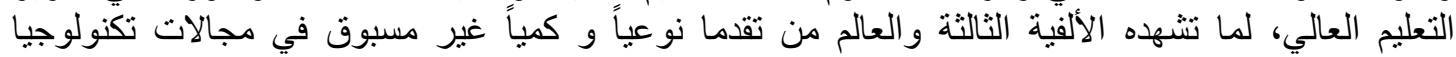

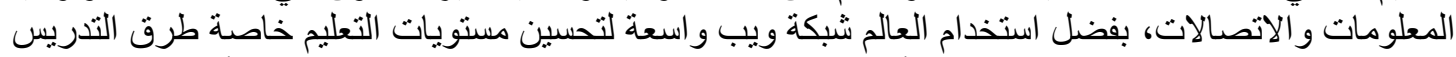

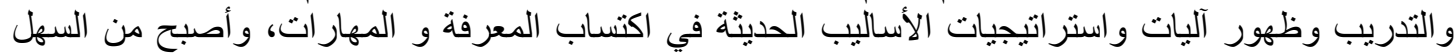

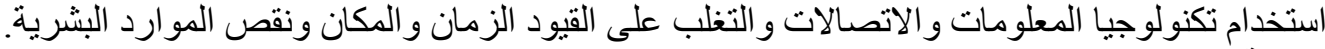

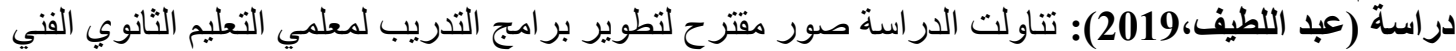

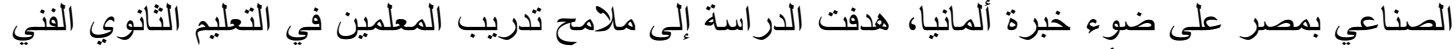

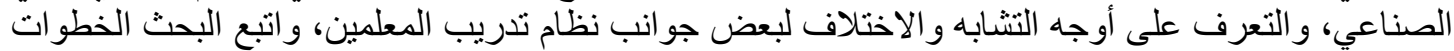

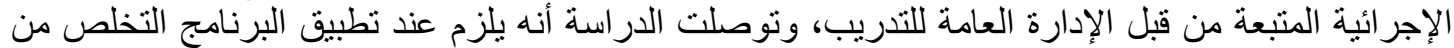

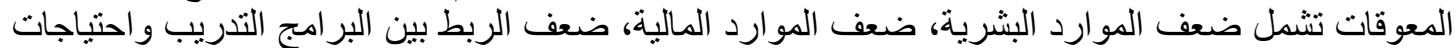

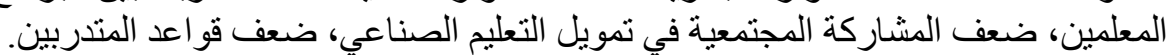

\section{دراسات المحور الثالث}

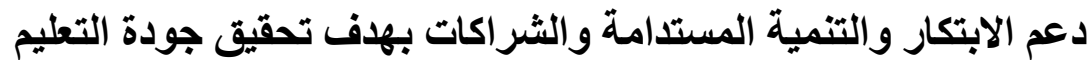

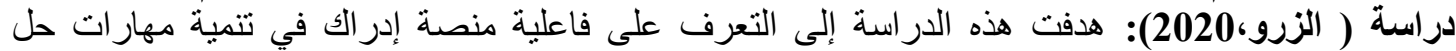

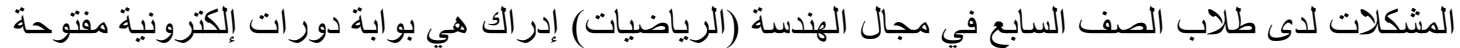

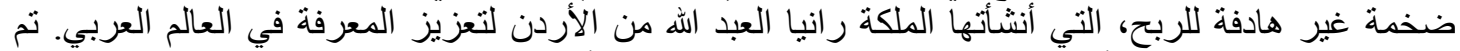

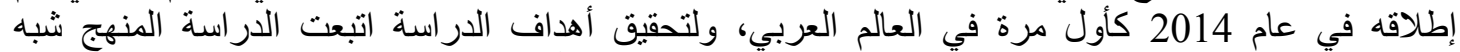

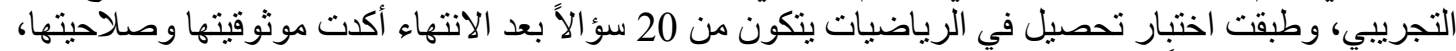

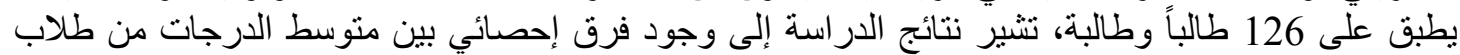

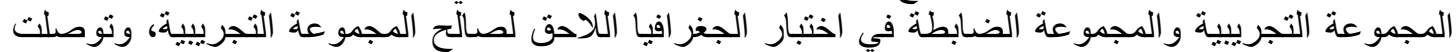

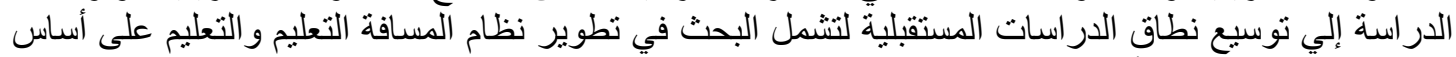

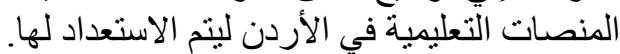

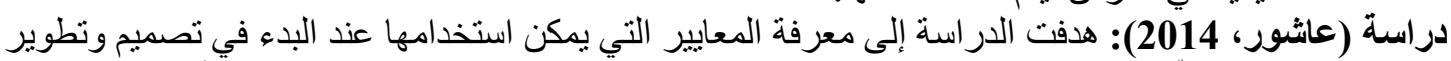

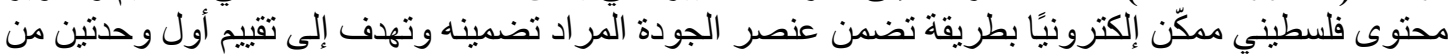

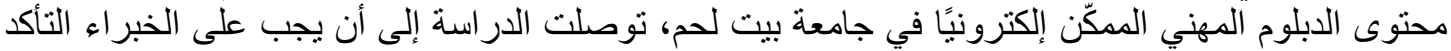




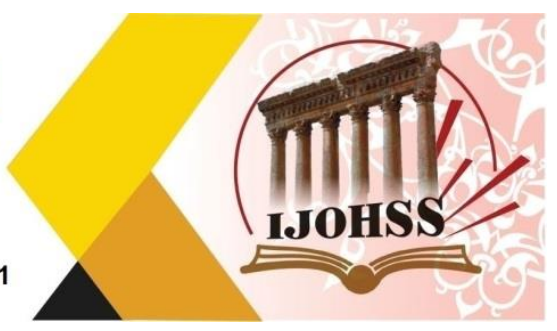

من المتعلمين عبر الإنترنت تم تحفيز هم بشكل صحيح من خلال تضمين العناصر التعليمية التي تجذب التبان انتباه

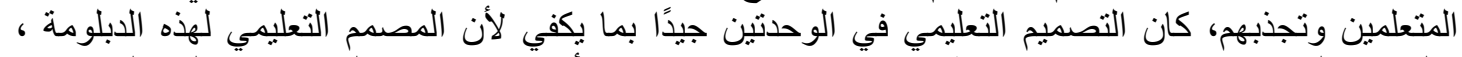

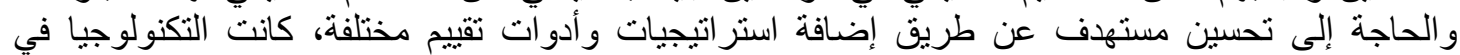
الوحدتين مرضية.

\section{دور أكاديميةٌ الملكة رانيا في دعم التطوير المهني للمعلم والقيادة التربوية دعما لجودة التعليم

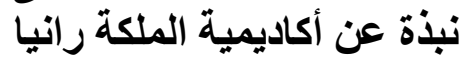

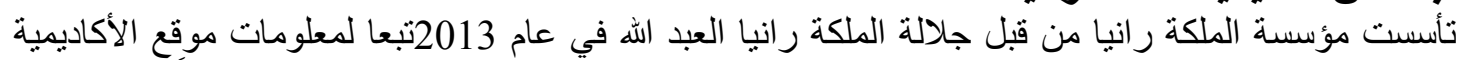

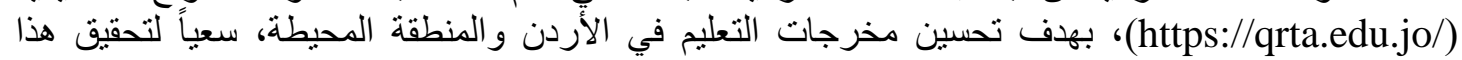

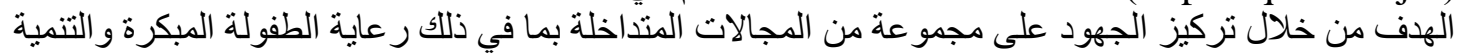

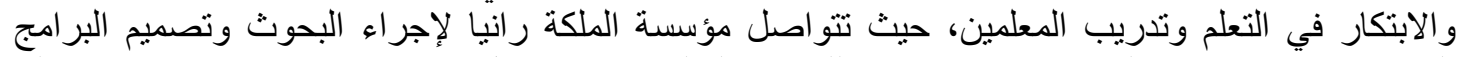

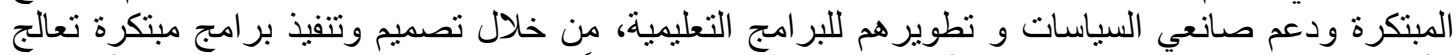

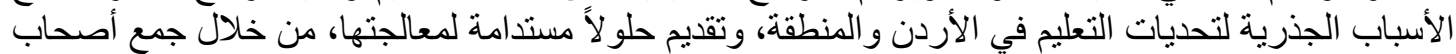

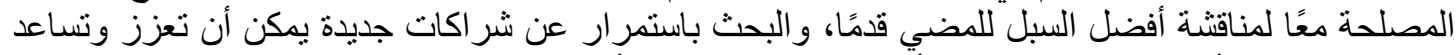

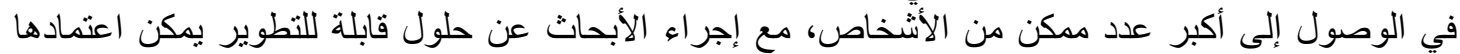

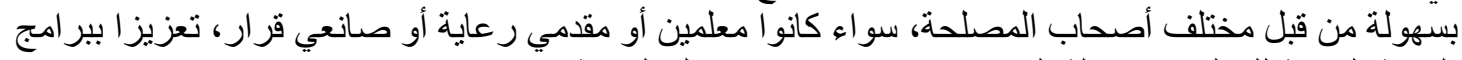

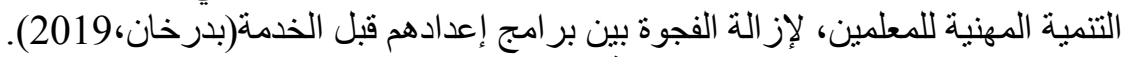

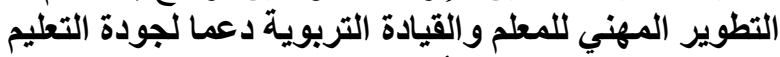

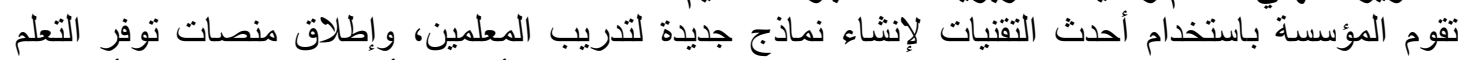

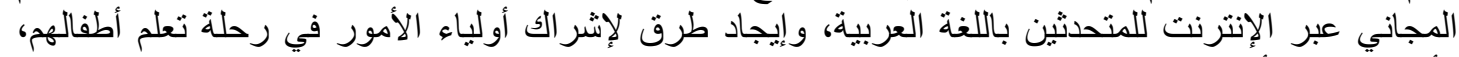

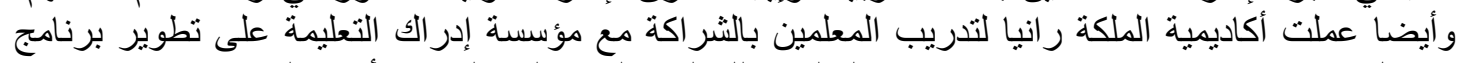

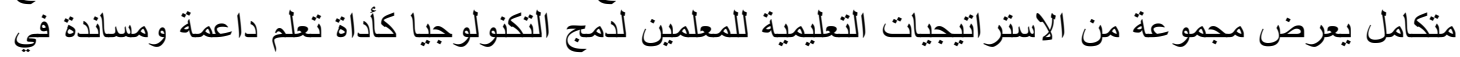

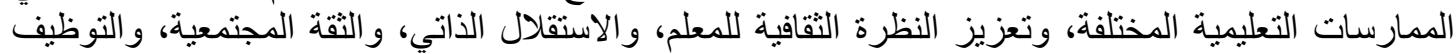

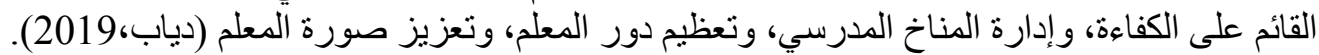

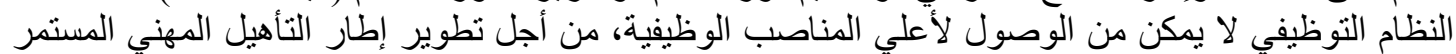

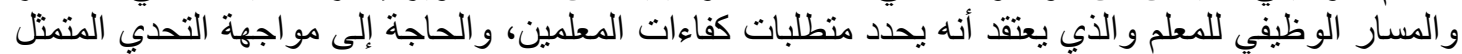

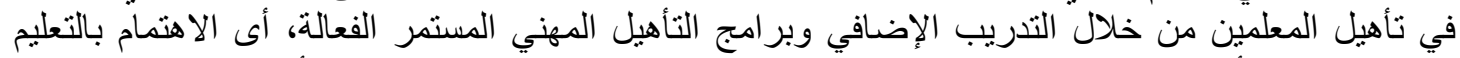

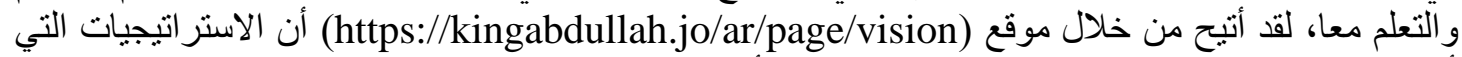

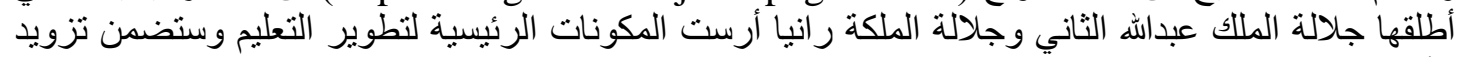

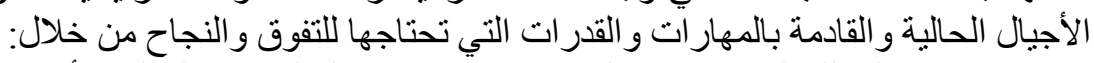

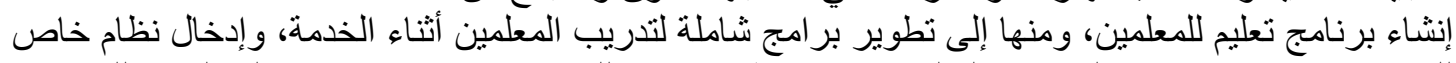

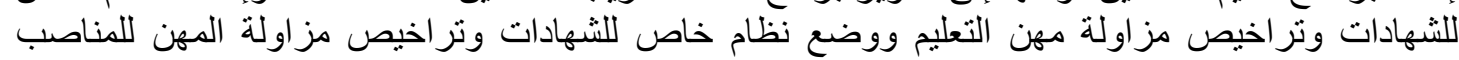

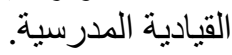

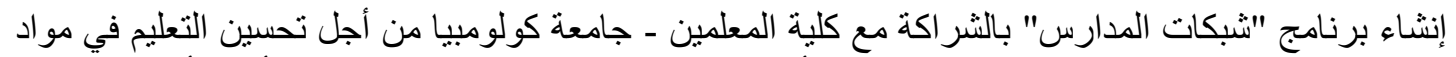

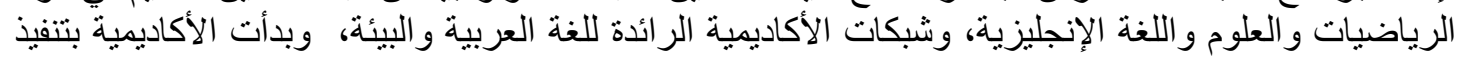

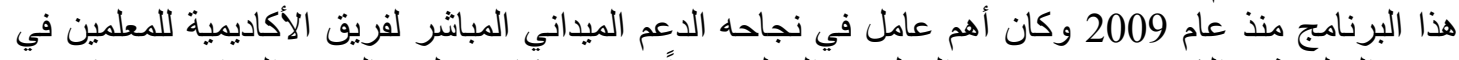

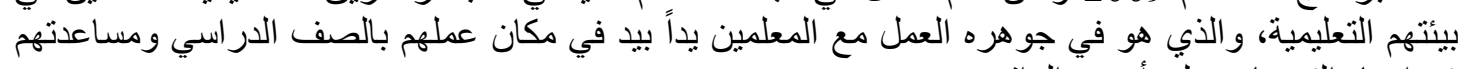

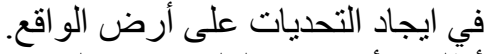

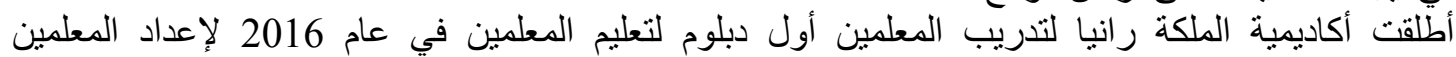

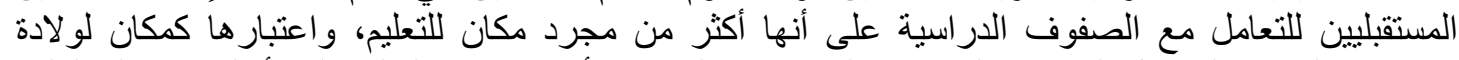

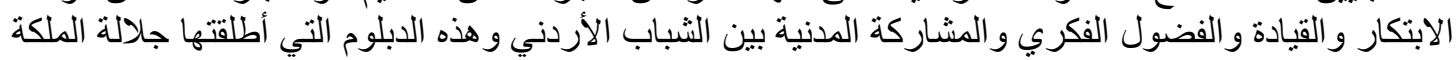




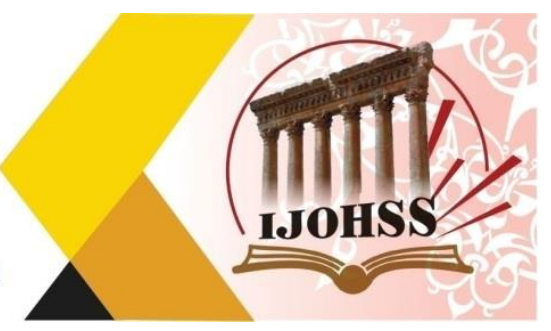

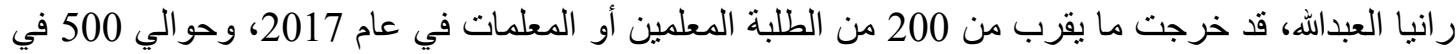

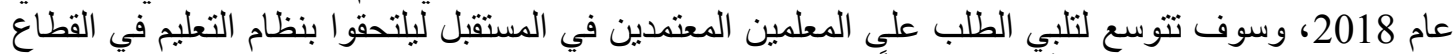

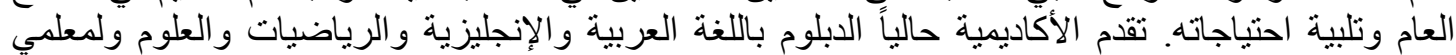
الصفوف الابتدائية،

يتم تدعيم بر امج أكاديمية الملكة رانيا لتدريب المعلمين من خلال الثر اكات الاستر اتيجية مع المنظمات الإنيات الدولية

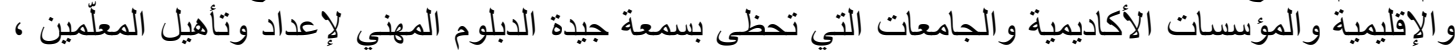

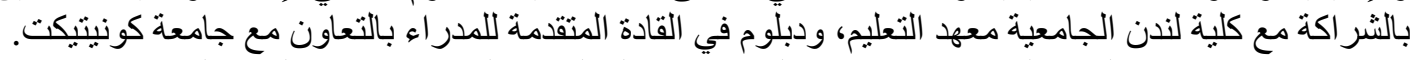

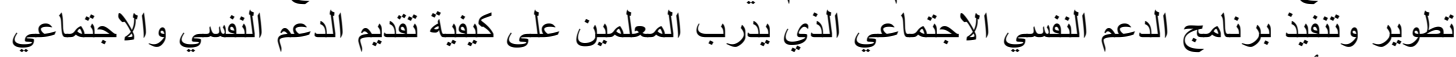

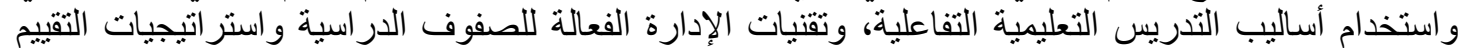

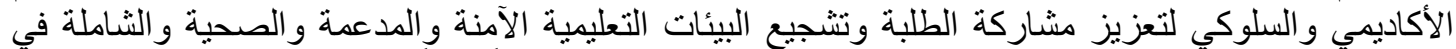

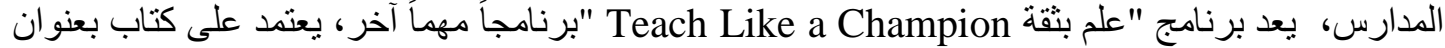
Teach Like a Champion

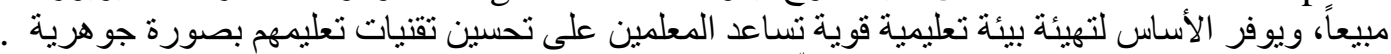

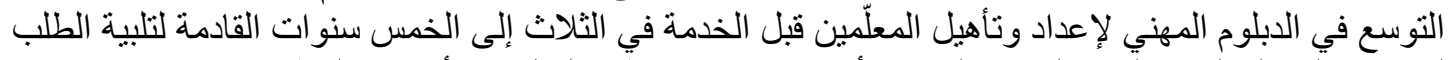

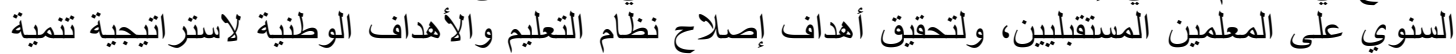

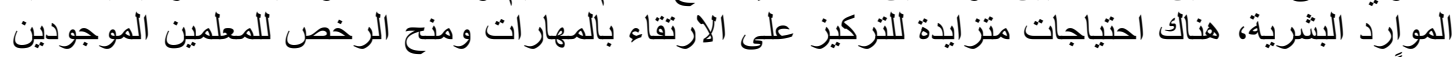

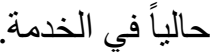

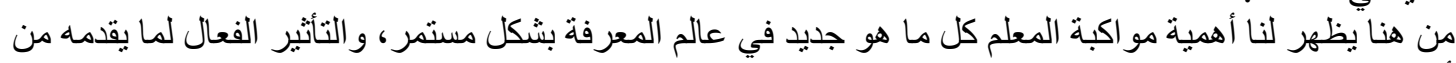

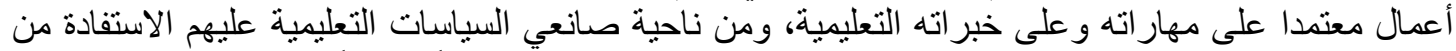

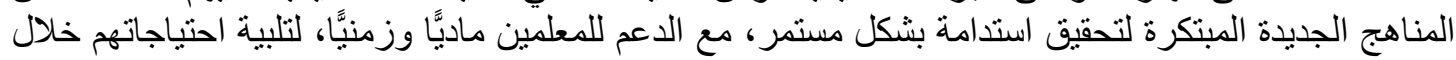
المر احل المختلفة من وظائفهم، ولتحقيق استدامة النمو التهو المهني (محمد، 2018).

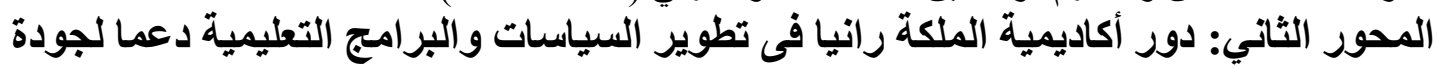

الأهداف التعزيزة للتعليم في ضوء التنمية المستدامة 2030

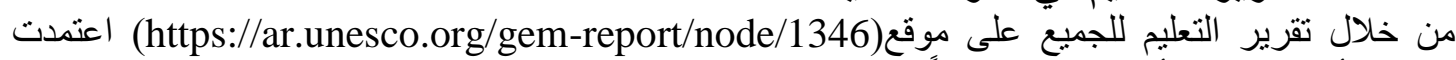

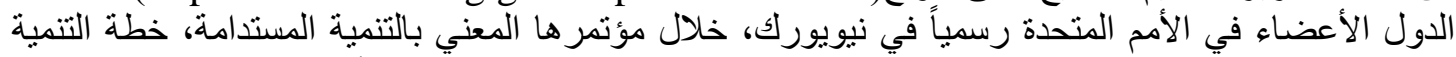

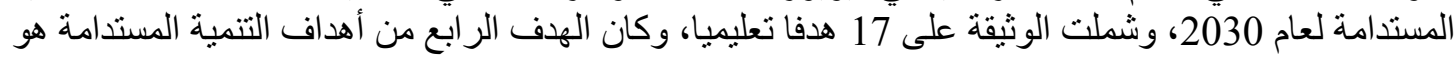

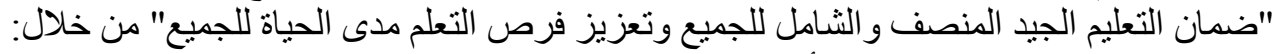

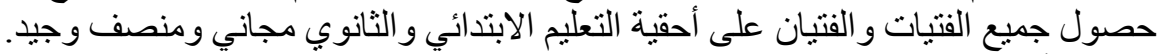

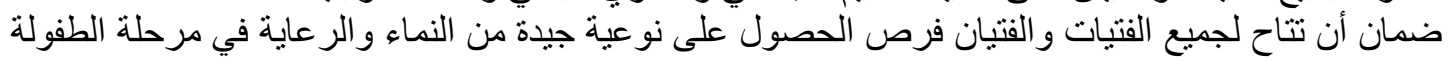

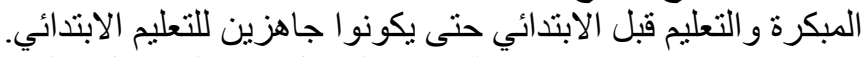

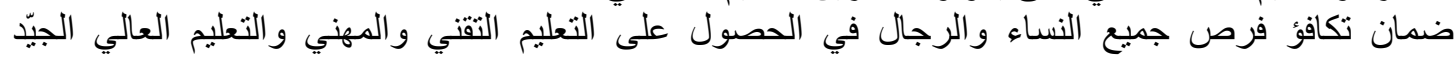

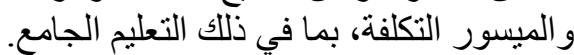

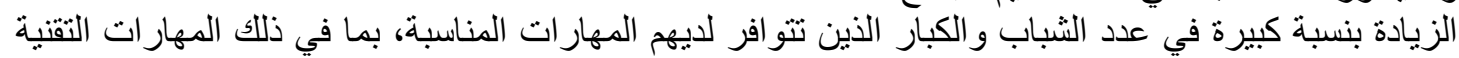
و المهنية، للعمل وشغل وشئ وظائف لائقة ولمبانشرة الأعمال الحرة.

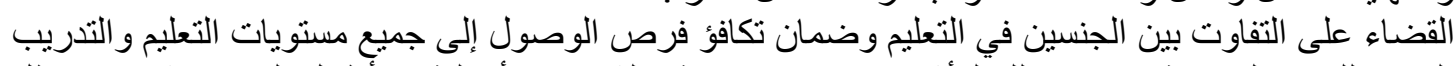

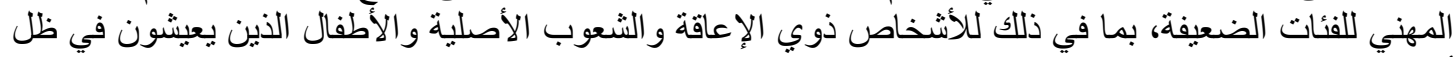
أوضاع هشة. ضمان أن يلم جميع الثباب ونسبة كبيرة من الكبار ، رجالاً ونساء على حد سواء، بالقر اءة والكتابة و الحساب.

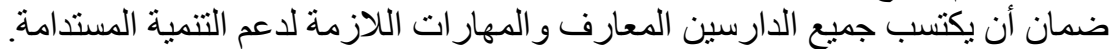

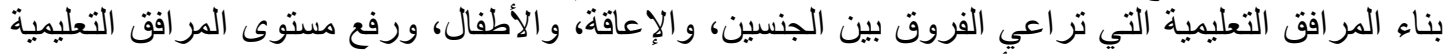
القائمة وتهيئة بيئة تعليمية فعالة و مأمونة وخالية من العنف للجئة الجميع. 
International Journal on Humanities and Social Sciences

website:www.ijohss.com

Email:editor@ijohss.com

العدد (27) نوفمبر 2021

ISSN: $2415-4822$

Volume (27) November 2021

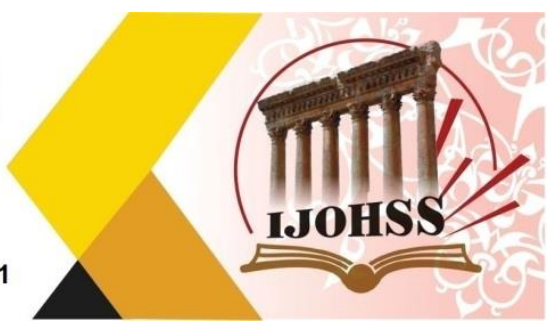

الزيادة بنسبة كبيرة في عدد المنح الدراسية المتاحة للبلدان النامية على الصعيد العالمي، وبخاصة لأقل البلدان نموا و الدول الجزرية الصغيرة النامية و البلدان الأفريقية.

الأسـاليب المستخدمة من قبل الأكاديمية لرعاية الإية الطقولة المبلة المبكرة من أجل الابتكار في التعليم

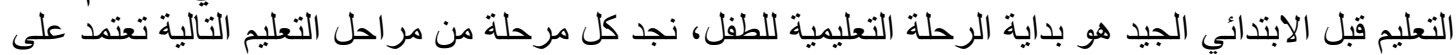

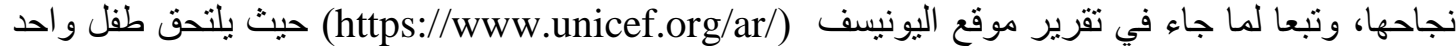

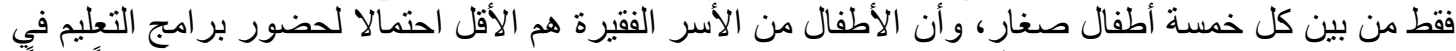

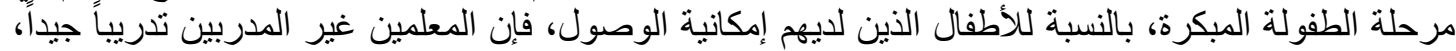

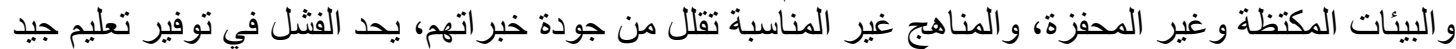

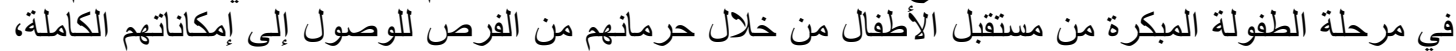

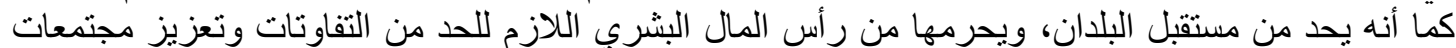

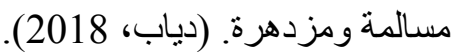

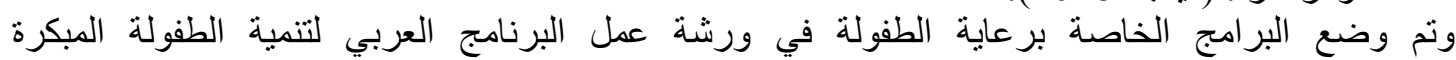

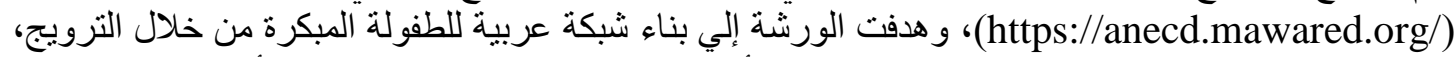

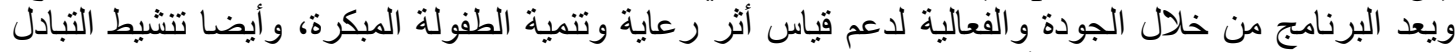

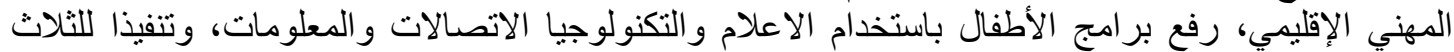

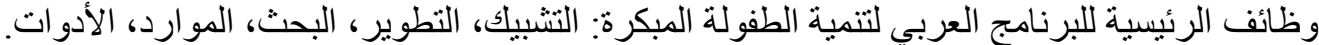

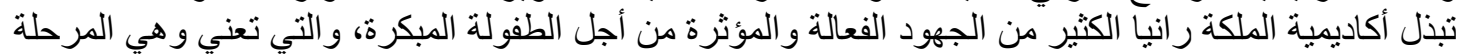

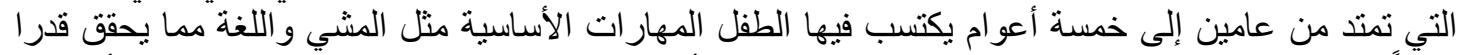

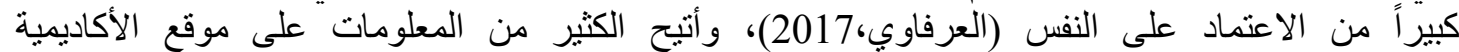

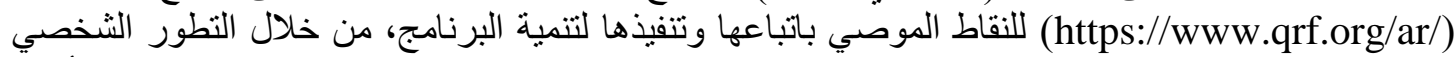

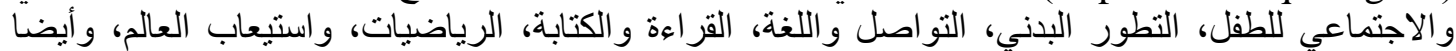

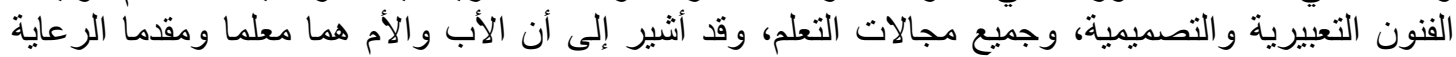

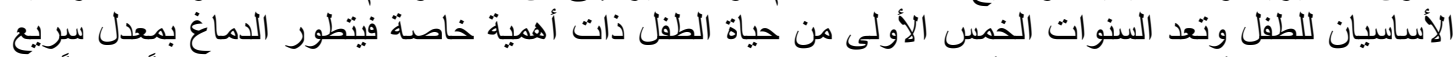

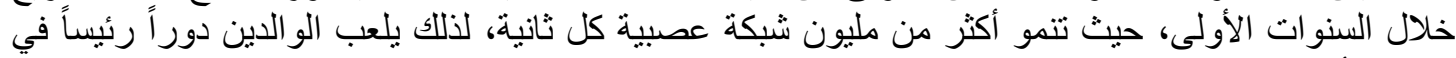

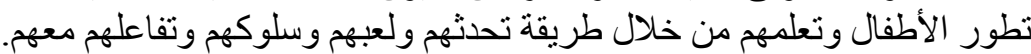

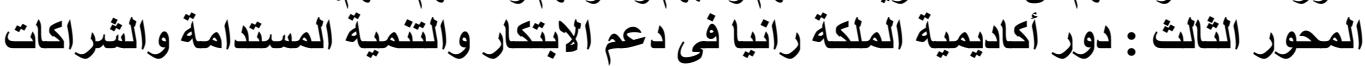
بهاف تحقيق جودة التعليم

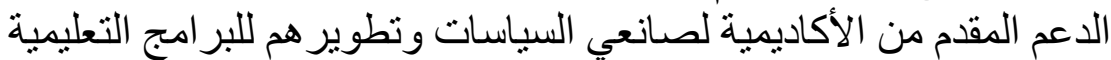

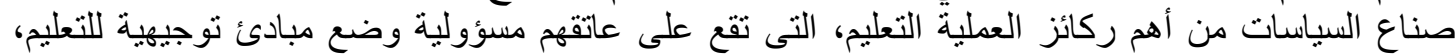

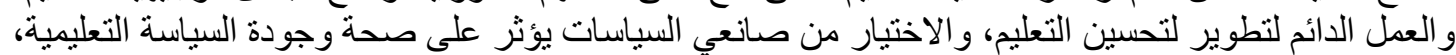

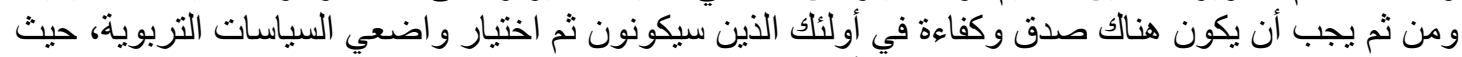

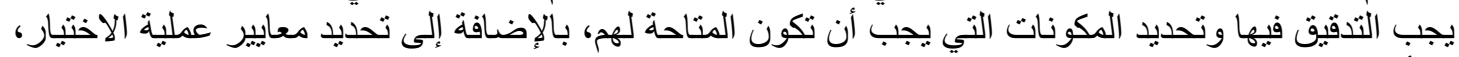

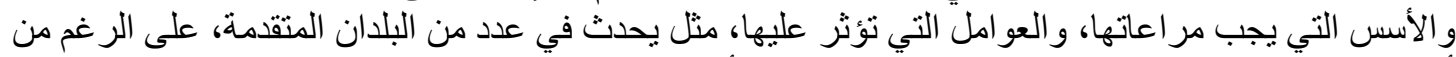

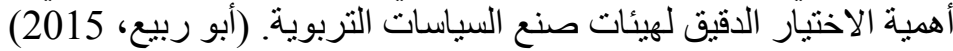

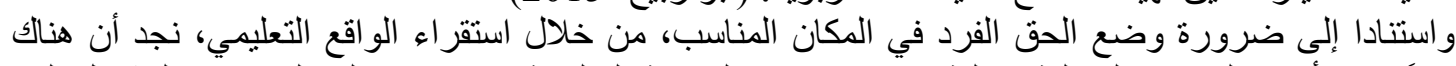

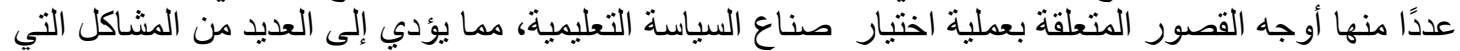

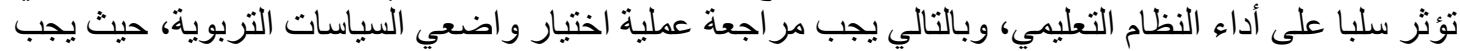

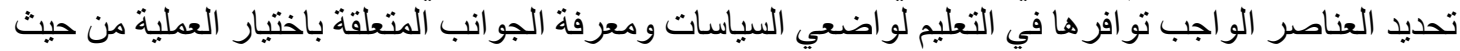

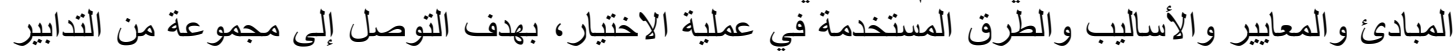
المقترحة التي من شأنها تطوير عملية اختيار صانعي السياسات التربوية. 


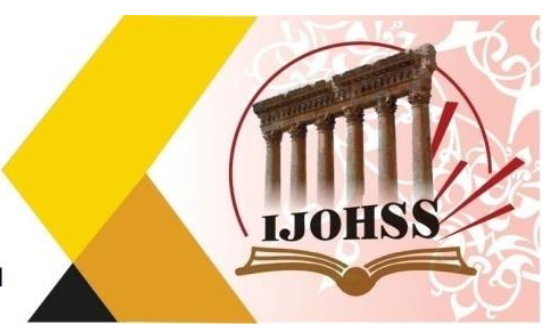

دور الثر اكة بين الأكاديمية ومنصة إدراك التعليمية في تحقيق جودة التعليم

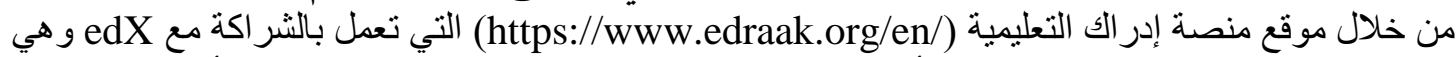

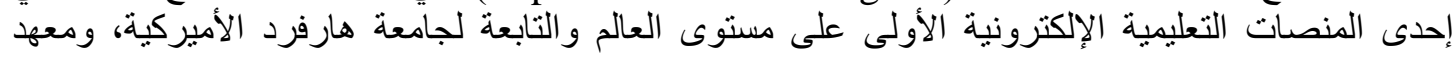

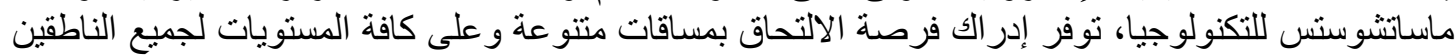

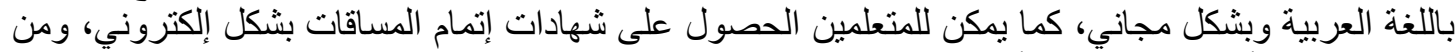

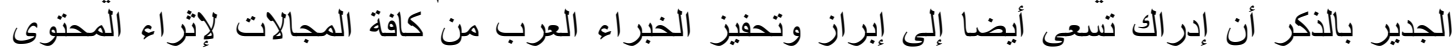

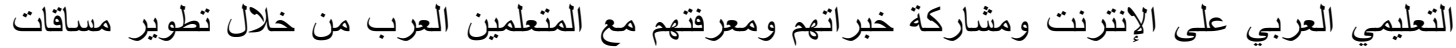
ونعرحها عبر المنصة.

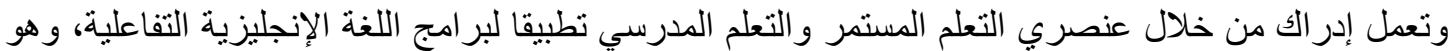

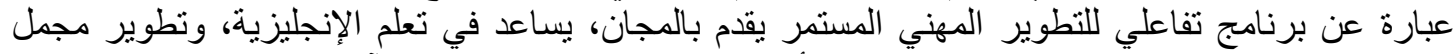

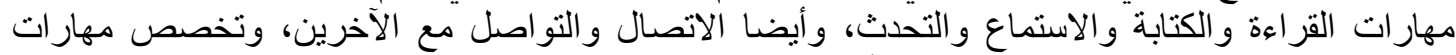

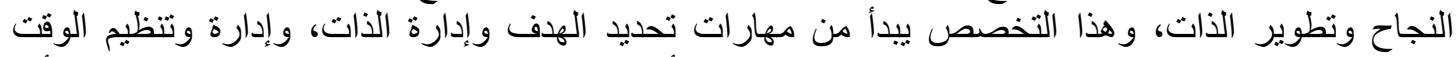

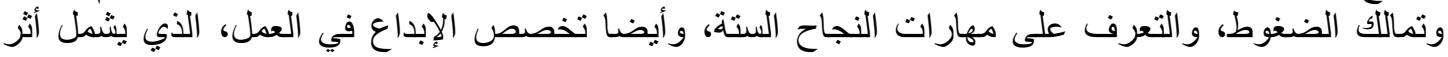

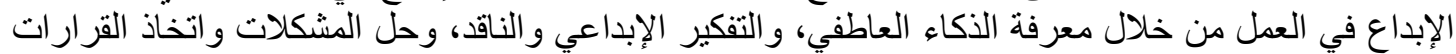

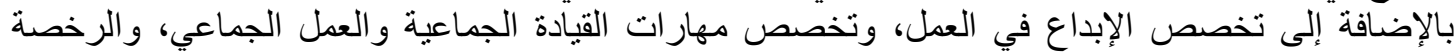

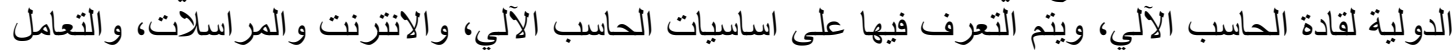

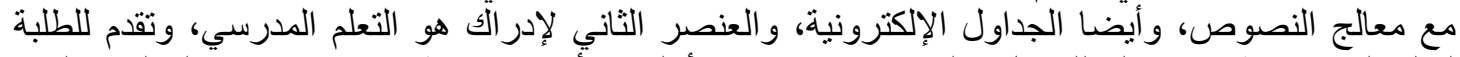

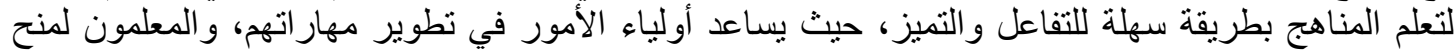

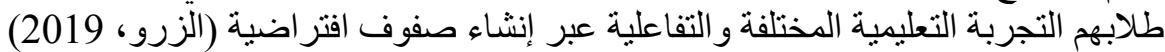

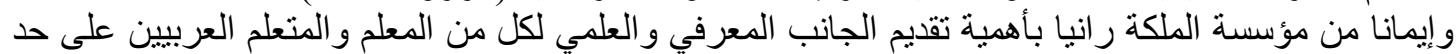

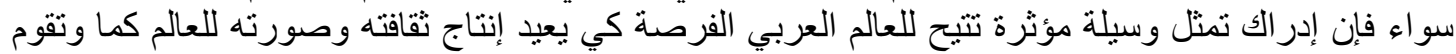

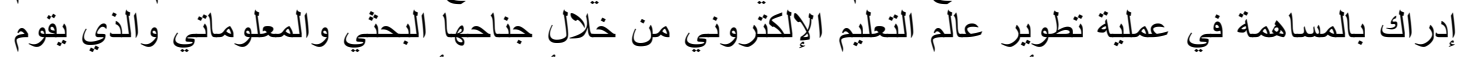

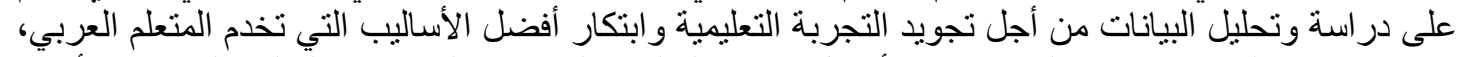

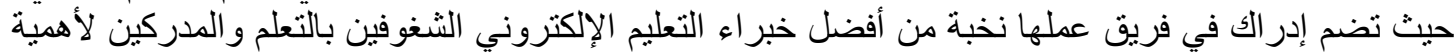

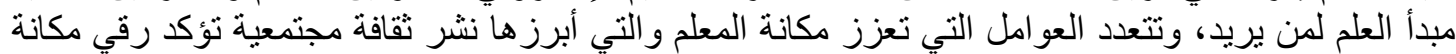
المعلم في المجتمع، وتبني حملات دعائية لتأكيد أهمية مهنة التعليم، ومن ثم جذب التبانية الاهتمام نحو المعلم كقيمة

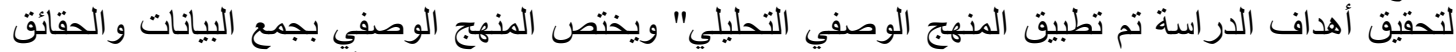

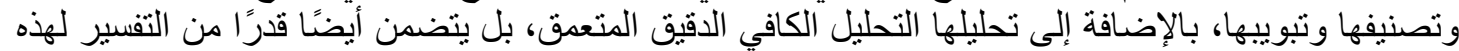

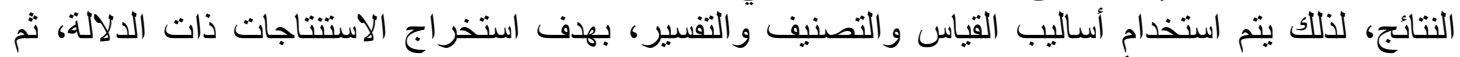

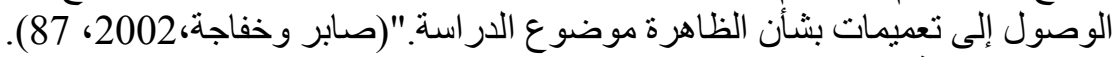

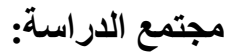
تكون مجتمع الدر اسة من المشاركين و المنتسبين و المتعاملين مع خدمات أكاديمية الملكة ر انيا

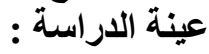

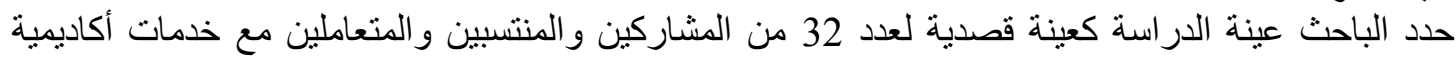
الملكة رانيا لتمثيل مجتمع الدر اسة الميدانية، كما تم تطبيق الدر اسة الوصفية بتطبيق استبانة على العينة القصدية. 


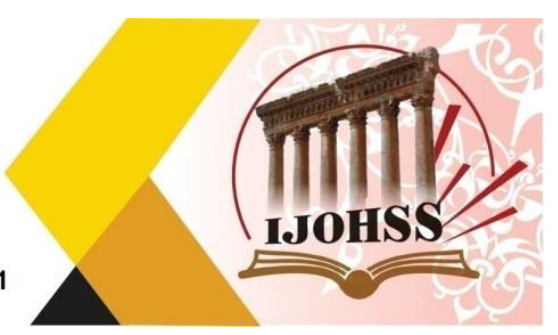

\begin{tabular}{|c|c|c|c|}
\hline \multicolumn{4}{|c|}{ جذول رقم (1) وصف العينة تبعا لمتغيري المؤهل التعليمي وسنوات الخبرة } \\
\hline \%ة"il| & 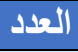 & الأفئات & المتضميز \\
\hline 84.4 & 27 & بكالوريوس/ليسانس & \multirow{4}{*}{ التعليمي هل } \\
\hline 12.5 & 4 & ماجستير & \\
\hline 3.1 & 1 & دكتور اه - اه & \\
\hline$\% 100$ & 32 & 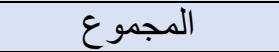 & \\
\hline$\% 25$ & 8 & 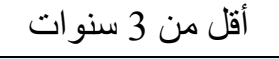 & \multirow{3}{*}{ سنوات الخبرة } \\
\hline$\% 46.9$ & 15 & من 4 إلى 7 سنو ات & \\
\hline$\% 28.1$ & 9 & أكثر من 7 سنوات & \\
\hline
\end{tabular}

وصف العينة:

كان هناك تجانس بين العينة أولا من حيث المؤهل التعليمي بانحراف معياري (0.471) بأغلبية من حملة

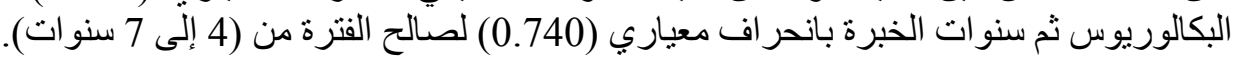

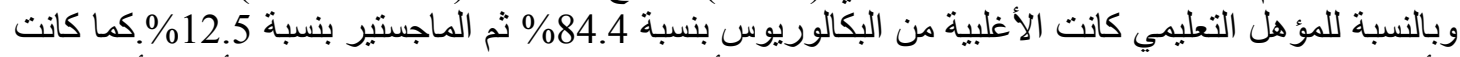

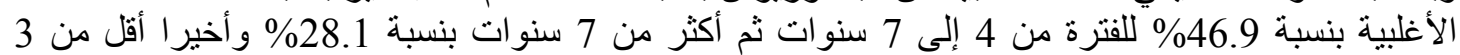
سنوات بنسبة 25\%. أداة الاراسة اتنة

بعد الاطلاع على الأدبيات و الدراسات السابقة ذات الصلة بموضو ع الدار الدراسة، قام الباحث بإعداد استبانة موجهة إلى عدد 32 من المشاركين و المنتسبين و المتعاملين مع خدمات الكادينة الكاديمية الملكة رانيا.

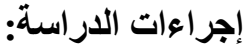
تم الاطلاع على العديد من الدراسات و البحوث الدانة السابقة في مجال الدر اسة

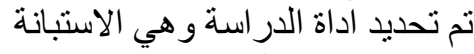

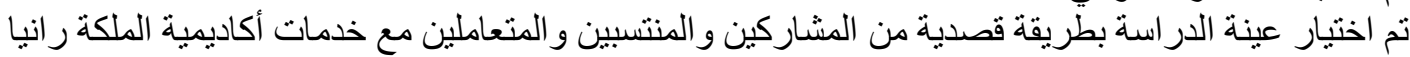

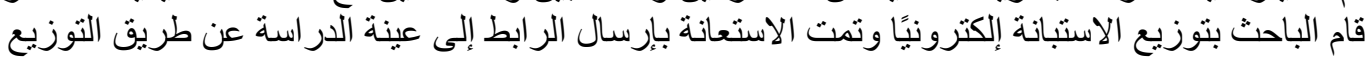

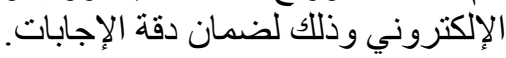

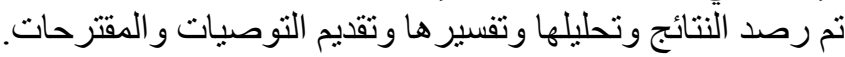

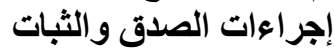

تم عرض أداة الدراسة على الثى المحكمين للتأكد من صلاحيتها ومناسبتها لتساؤلات الدر اسة، ومن ثم القيام بإجر اء ما

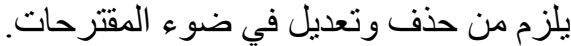
تم تطبيق أداة الدر اسة " الاستبيان" على عينة استطلاعية قو امها 10 مفردات ذلك بهدف التحقق من صدق وثبات

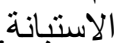

جدول رقم (2 ) معامل ألفا كرونباخ للمحاور الثلاثة

إحصائيات الثبات

\begin{tabular}{|c|c|c|c|}
\hline معامل ألفا كرونباخ & عدد الانبود & المحاور & م \\
\hline 0.763 & 10 & المحور 1 & 1 \\
\hline 0.898 & 10 & المحور2 & 2 \\
\hline 0.115 & 10 & المحور 3 & 3 \\
\hline 0.856 & 30 & المستوى الكلي للأداة & \\
\hline
\end{tabular}

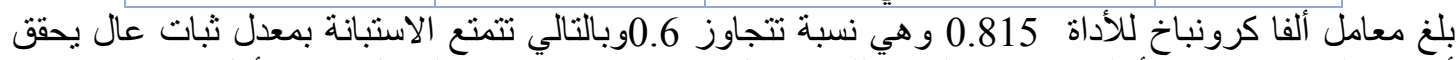
أهداف الدراسة وكانت أعلى درجات الثات الثبات للمحور الثاني بدرجة بينما حقق المحور الثالث أقل درجة ثلثات درجات الثات المات 
المجلة الحولية اللملوم الأسانية والإمتصاعية International Journal on Humanities and Social Sciences websiterwww.ijohss.com Email:editor@ijohss.com العدد (27) نوفمبر 2021 ISSN: $2415-4822$

Volume (27) November 2021

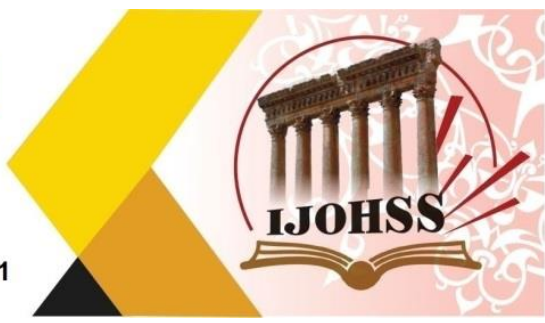

وبذلك يكون مجموع العبار ات 30 عبارة تم تحديد الإجابة عليها تبعاً لمقياس ليكرت المتدرج من خمس إجابات

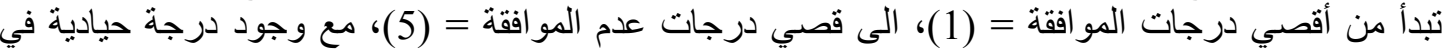

\begin{tabular}{|c|c|c|c|c|c|}
\hline بشداة & لا أوافق & محايد & أوافق & أوافق بشدة & الاستجابة \\
\hline 1 & 2 & 3 & 4 & 5 & الارجة \\
\hline
\end{tabular}

\begin{tabular}{|c|c|c|c|}
\hline در حة المو افقة & المو اققة & خبا, المه (فقة & فئة المته سط الدسياس \\
\hline منخفضة حدا & $\% 36$ & غير موافق بشدة & 1.8 \\
\hline منخفضة & $\% 52.9$ - \%36.1 & غير موافق & $2.6-1.81$ \\
\hline متوسطة & $\% 68.9$ - \%35 & محايد & $3.4-2.61$ \\
\hline كبيرة & $\% 84.9$-\%69 & موافق & $4.2-3.41$ \\
\hline كبيرة جذا & $\% 100$ - \%85 & موافق بشدة & $5-4.21$ \\
\hline
\end{tabular}

الأساليب الإحصائية

بناء على طبيعة البحث والأهداف التئي سعى إلى تحقيقها، تم تحليل البيانات باستخدام برنامج الحزمة الإحصائية

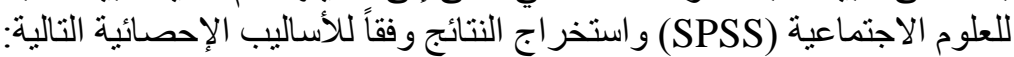
معامل ألفا كرونباخ: لحساب التبات الثبات لأبعاد الاستبانة.

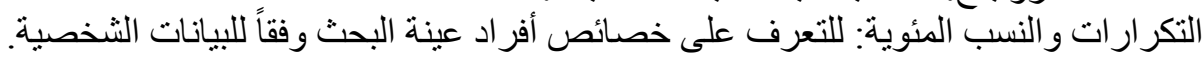

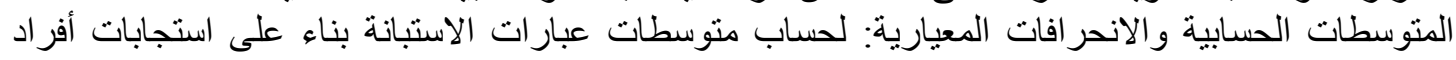

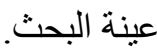
عرض نتائج الدراسة ومناقشتها.

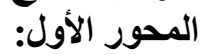
دور أكاديمية الملكة رانيا في دعم التطوير المهني للمعلم والقيادة التربوية دعما لجودة التعليم

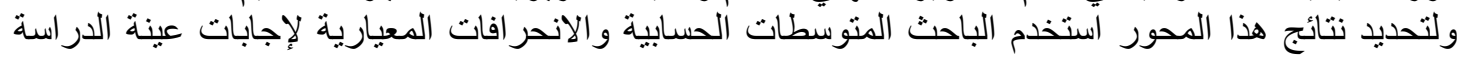

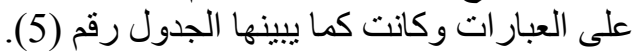

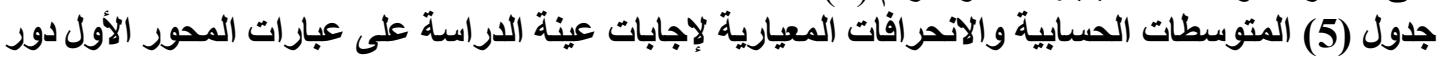
أكاديمية الملكة رانيا في دعم التطوير المهني للمعلم والقيادة التربوية دعما لجودة التئة التعليم.

\begin{tabular}{|c|c|c|c|c|c|}
\hline التقدير & الرتبة & 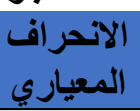 & 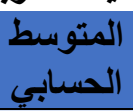 & 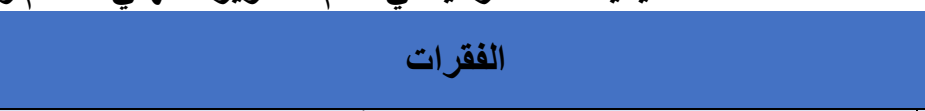 & r \\
\hline 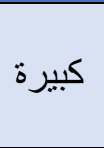 & 4 & 0.87 & 3.56 & 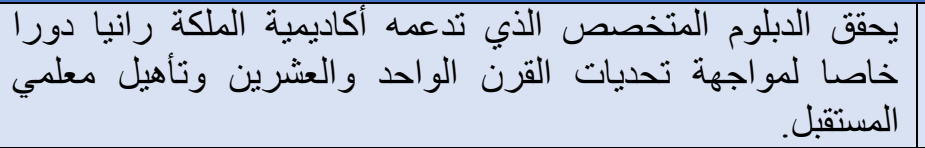 & 1 \\
\hline كبيرة & 4 & 0.87 & 3.59 & تتبنى أكاديمية الملكة ر انيا جهودا لتطوير المعلم محليا و عربيا. & 2 \\
\hline 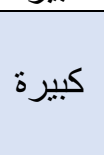 & 2 & 0.45 & 3.84 & 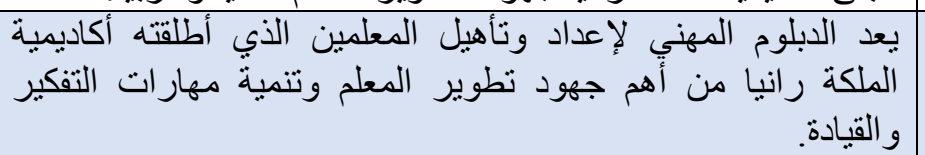 & 3 \\
\hline كبيرة & 2 & 0.47 & 3.81 & تهنت أكاديمية الملكة رانيا بتأهيل العنصر البشري ليتلاءم مع & 4 \\
\hline كبيرة & 2 & 0.48 & 3.66 & 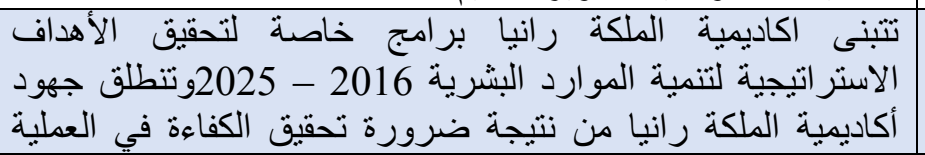 & 5 \\
\hline
\end{tabular}


المجلة الحولية اللعلوم الآنسانية والإمتاعاعية International Journal on Humanities and Social Sciences websiterwww.ijohss.com Email:editor@ijohss.com

العدد (27) نوفمبر 2021 ISSN: $2415-4822$

Volume (27) November 2021

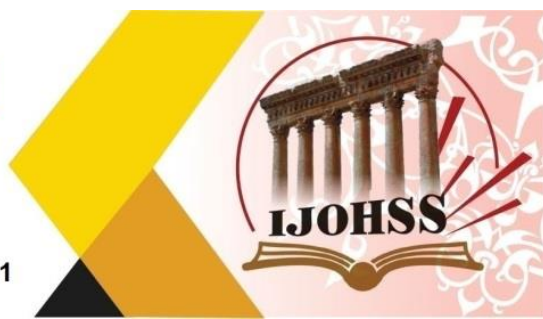

\begin{tabular}{|c|c|c|c|c|c|}
\hline & & & & التعليمية من خلال بر امج تدريب المعلم قبل و أنثناء الخدمة. & \\
\hline كبيرة & 1 & 0.53 & 3.69 & تتبنى أكاديمية الملكة مبداً أن المعلم هو المفتاح لعصرنة التعليم. & 6 \\
\hline كبيرة & 2 & 0.84 & 3.59 & جودة التعليم. مهار ات المعلمين أحد أهم مبادرات الأكاديمية لتعزيز & 7 \\
\hline كبيرة & 4 & 0.49 & 3.78 & 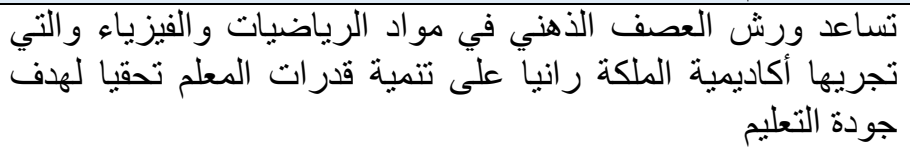 & 8 \\
\hline متوسطة & 3 & 1.150 & 2.97 & تتتبنى أكاديمية الملكة رانيا بر امج لتعزيز استخدام التكنولوجيا في & 9 \\
\hline متوسطة & 3 & 1.201 & 2.91 & ترعى أكاديمية الملكة رانيا بر امج خاصة لتطوير المناهج التعليمية. & 10 \\
\hline 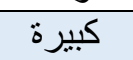 & 2.7 & 0.74 & 3.54 & المتوسط الكلي للمحور & 11 \\
\hline
\end{tabular}

جاءت استجابة العينة على فقرات المحور الأول للتعرف على دلى دور أكاديمية الملكة رانيا في دعم التطوير المهني

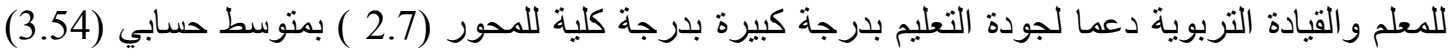

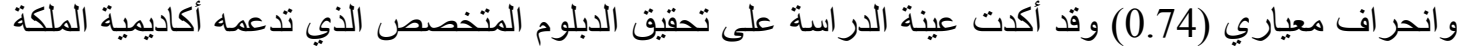

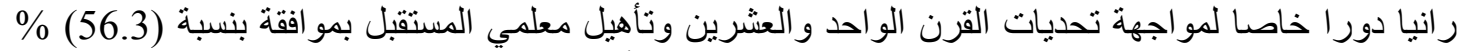

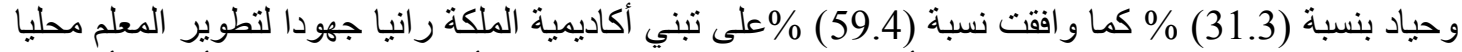
و عربيا، ووافقت نسبة (78.1\%). على أنى أنه بعد الدبلوم المهني لإعداد وتأهيل المعلمين الذي أطلقته أكاديمية

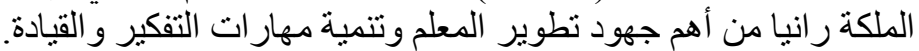

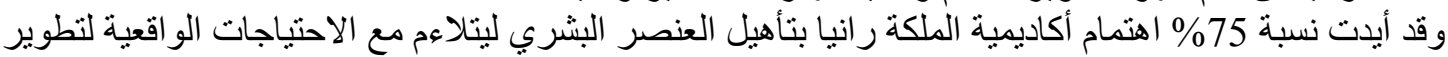

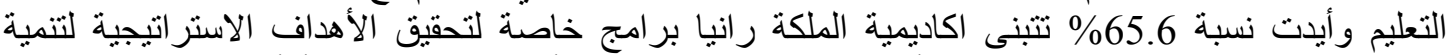

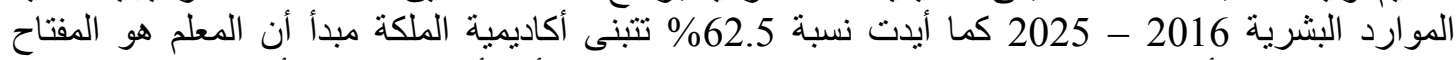
لعصرنة التعليم، و أيدت نسبة 65.6\% اعتبار ملتقى مهار ات المعلمين أحد أهم مبادرات الأكاديمية لتنعزيز جودة المباح التعليح. و أكدت نسبة 71.9\% مساعدة ورش العصف الذهني في مواد الرياضيات و الفيزياء و التي تجريها أكاديمية الملكة

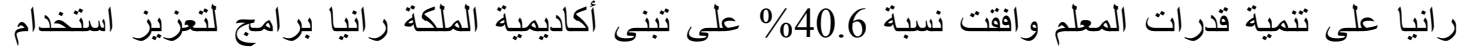

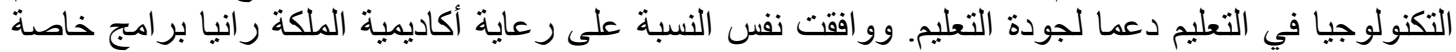
لتطوير المناهج التعليمية. المحور الثاني النيج

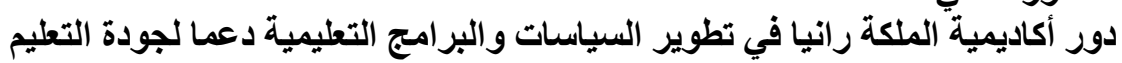

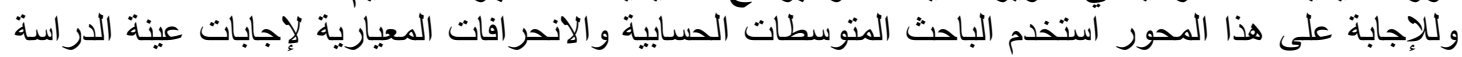

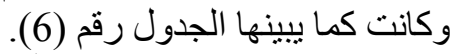

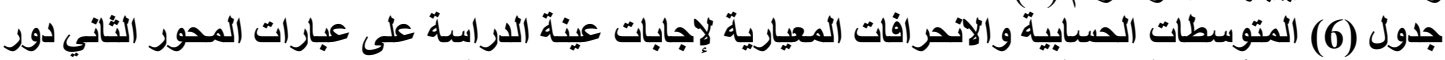

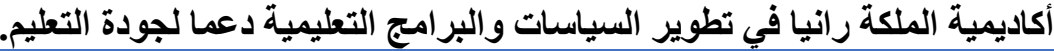

\begin{tabular}{|c|c|c|c|c|c|}
\hline التقدير & الرتبة & 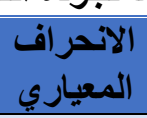 & 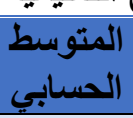 & 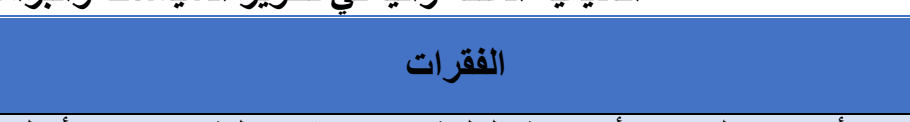 & r \\
\hline 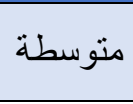 & 3 & 1.22 & 3.16 & 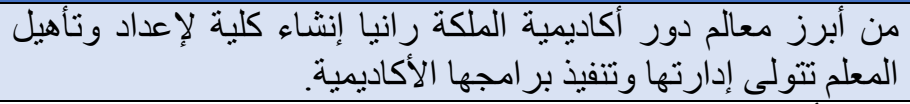 & 1 \\
\hline 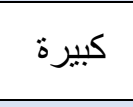 & 3 & 0.80 & 3.44 & إطتبنى أكاديمية الملكة رانيا تطوير إجر اءوات تعيين و اختيار المعلم في & 2 \\
\hline كبيرة & 3 & 1.10 & 3.41 & 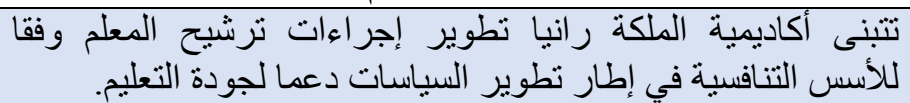 & 3 \\
\hline متوسطة & 4 & 1.04 & 3.38 & تتبنى أكاديمية الملكة رانبا تحسين ظروف المعلم من خلال زيادة & 4 \\
\hline
\end{tabular}


المجلة الحولية اللعلوم الآنسانية والإمتاعاعية International Journal on Humanities and Social Sciences websiterwww.ijohss.com Email:editor@ijohss.com

العدد (27) نوفمبر 2021 ISSN: $2415-4822$

Volume (27) November 2021

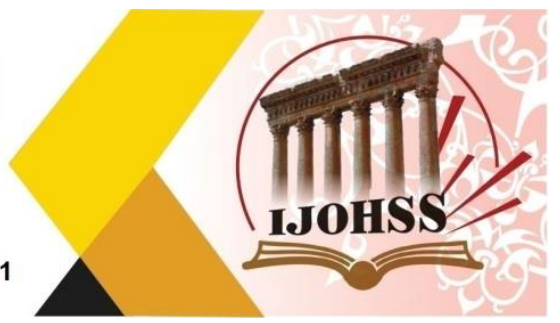

\begin{tabular}{|c|c|c|c|c|c|}
\hline & & & & لجودة التعليم. التب وافظ وفقا للتقام الوظيفي في إطار تطوير السياسات دعما & \\
\hline متوسطة & 3 & 1.14 & 3.16 & 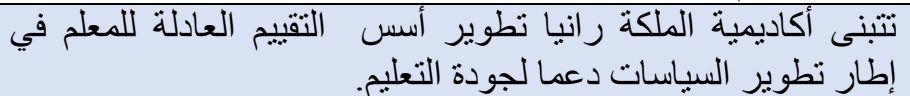 & 5 \\
\hline منوسطة & 3 & 1.15 & 3.19 & 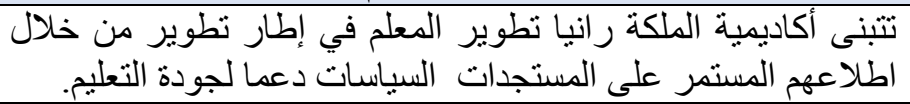 & 6 \\
\hline متوسطة & 3 & 1.10 & 3.38 & 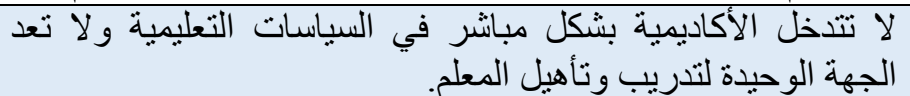 & 7 \\
\hline متوسطة & 3 & 0.98 & 3.22 & 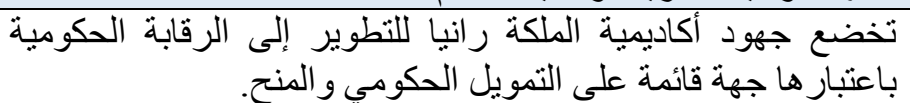 & 8 \\
\hline منوسطة & 3 & 0.95 & 3.16 & 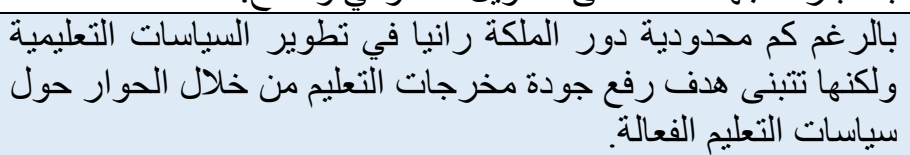 & 9 \\
\hline متوسطة & 3 & 0.96 & 3.09 & 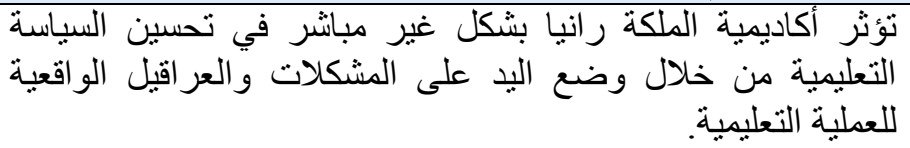 & 10 \\
\hline متوسطة & 3.1 & 1.04 & 3.26 & المتوسط الكلي للمحور & 11 \\
\hline
\end{tabular}

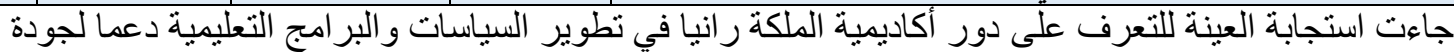

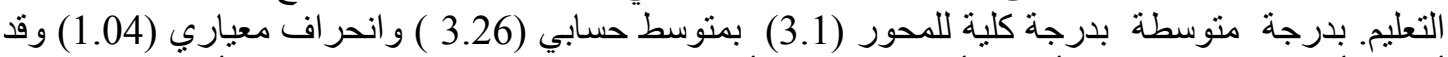

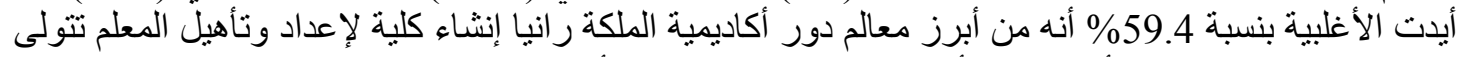

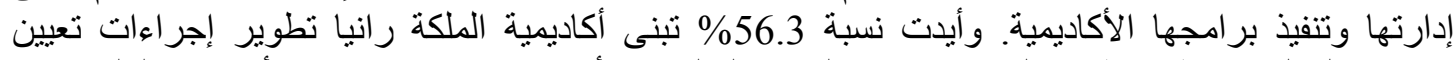
واختيار المعلم في إطار تطوير السياسات دعما لجودة التعليم كما أيدت نسبة تئسة

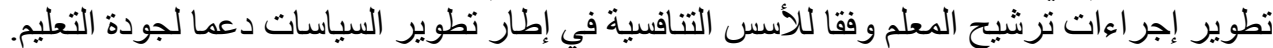

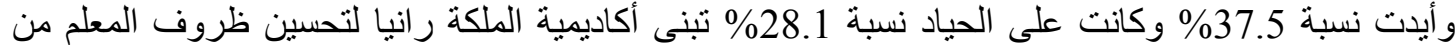

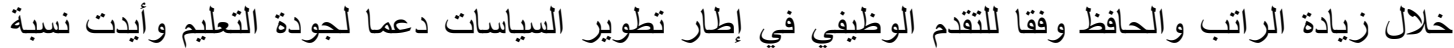

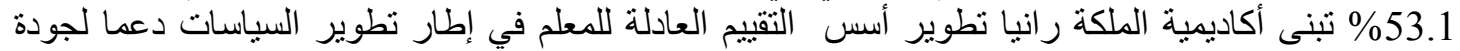
التعليم كما أيدت نسبة 56.3\% تبنى أكاديمية الملكة رانيا تطوير المعلم في إطار تطوير من خلادل اطلطاعهم

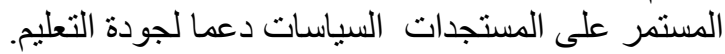

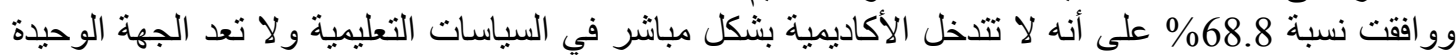

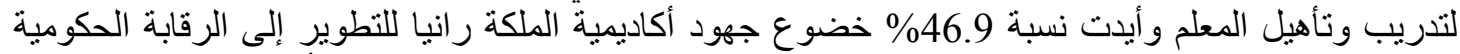

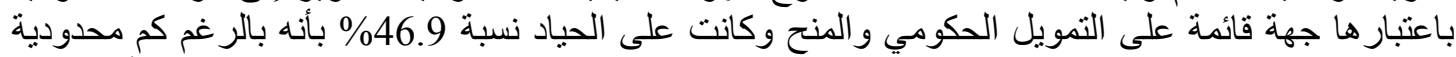

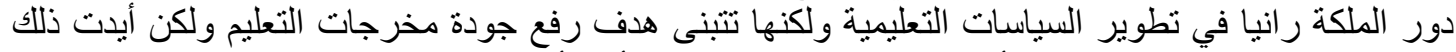
نسبة 40.6\% وكانت على الحياد أيضا نسبة 46.9\% بوجود تأثير أكاديمية الملكة ر رانيا بشكل غير مبانشر في تحسين السياسة التعليمية.

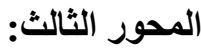

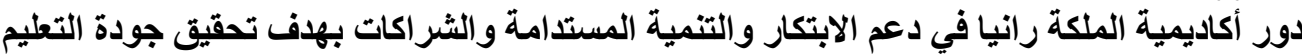

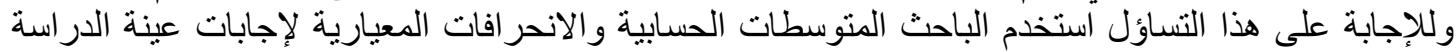
على عبار ات المحور الثالث وكانت كما يبينها الجدول رقم النمان (7). 
المجلة الحولية اللعلوم الآنسانية والإمتاعاعية International Journal on Humanities and Social Sciences website:www.ijohss.com Email:editor@ijohss.com

العدد (27) نوفمبر 2021 ISSN: $2415-4822$

Volume (27) November 2021

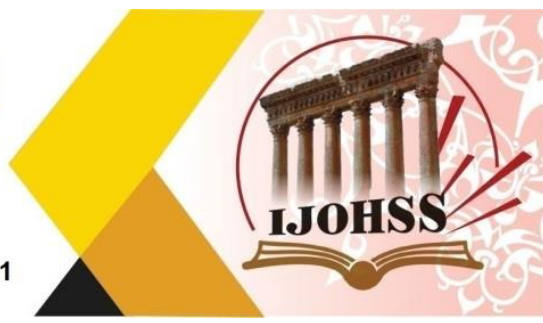

جدول (7) المتوسطات الحسابية والانحرافات المعيارية لإجابات عينة الاراسة على عبارات المحور الثالث دور

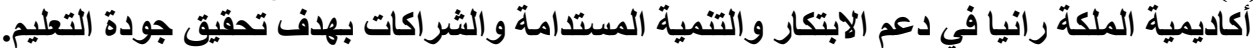

\begin{tabular}{|c|c|c|c|c|c|}
\hline التقدير & الرتبة & 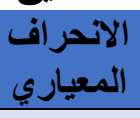 & 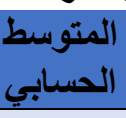 & : & م \\
\hline كبيرة & 4 & 0.72 & 3.94 & 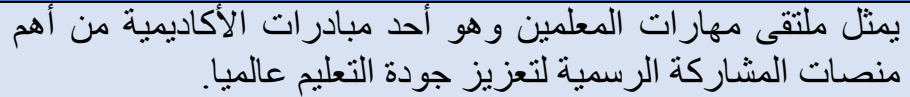 & 1 \\
\hline منوسطة & 3 & 0.85 & 3.28 & تخبت أكاديمية الملكة رانيا بتفعيل الاستكثاف و التعلم من خلال تبادل & 2 \\
\hline كبيرة & 2 & 0.62 & 3.94 & 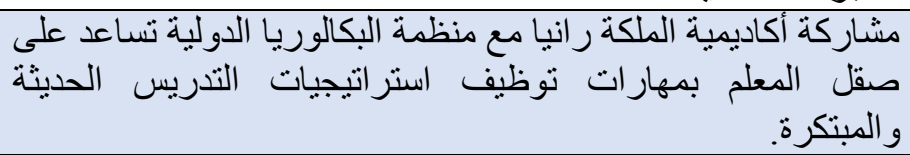 & 3 \\
\hline كبيرة & 1 & 0.42 & 3.78 & 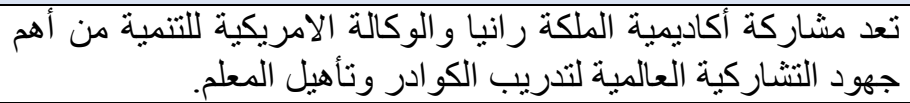 & 4 \\
\hline كبيرة & 4 & 0.95 & 3.53 & 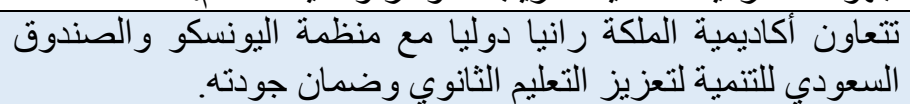 & 5 \\
\hline كبيرة & 3 & 0.59 & 3.81 & التعليى. أُكاديمية الملكة رانيا لتبني حلول مستدامة لحل الفجوات في & 6 \\
\hline منوسطة & 3 & 1.00 & 3.34 & لتشبنى أكاديمي الملكة رانيا بر امج مبتكرة للاستجابة السريعة و الفعالة & 7 \\
\hline كبيرة & 4 & 0.98 & 3.63 & البتبنى أكاديمية الملكة رانبا منهجية البحث و الثشر اكة لمضاعفة فاعلية & 8 \\
\hline كبيرة & 2 & 0.59 & 3.69 & 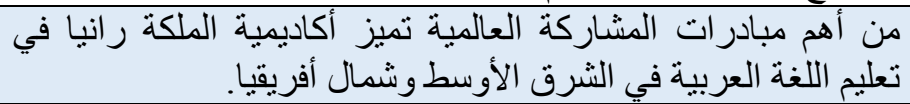 & 9 \\
\hline كبيرة & 2 & 0.61 & 3.41 & 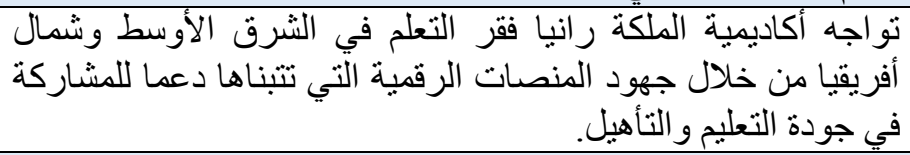 & 10 \\
\hline كبيرة & 2.8 & 0.73 & 3.64 & المتوسط الكلي للمحور & 11 \\
\hline
\end{tabular}

جاءت استجابة العينة للتعرف دور أكاديمية الملكة رانيا في دعم الابتكار والتنمية المستدامة والثر اكات التهات بهدف تحقيق جودة التعليم بدرجة كبيرة بدرجة كلية للححور (2.8) بمنوسط حسابي للاستجابات (3.64) وانحر اف معياري (0.73) (0.75) أيدت نسبة (75\%) اعتبار ملتقى مهار (073) ات المعلمين وهو أحد مبادرات الأكاديمية من أهم منصات المشاركة

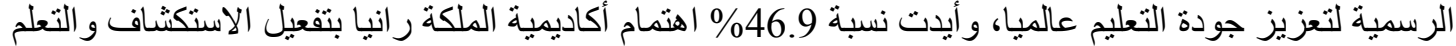

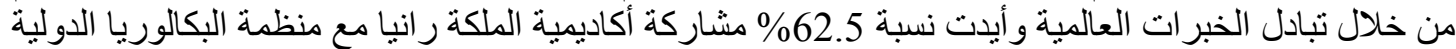

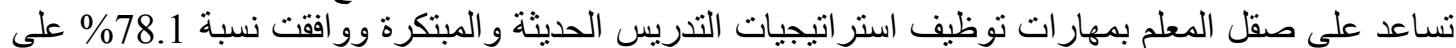
أنه تعد مشاركة أكاديمية الملكة رانيا و الوكالة الامريكية للتنمية من أهم جهود النشاركية العالمية لتدريب الكية الكوادر

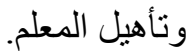

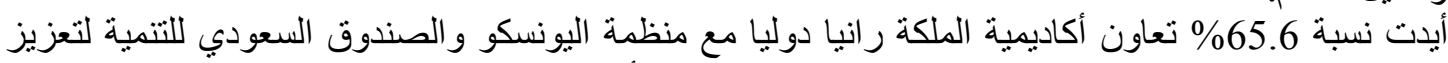

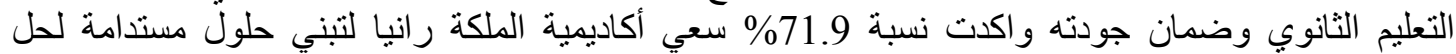

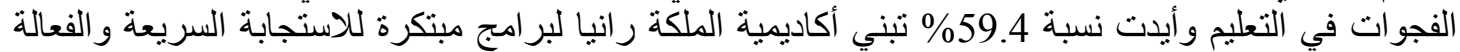

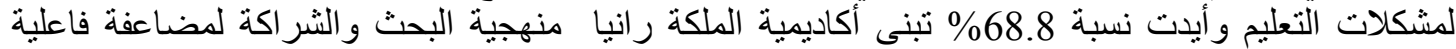

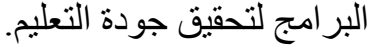




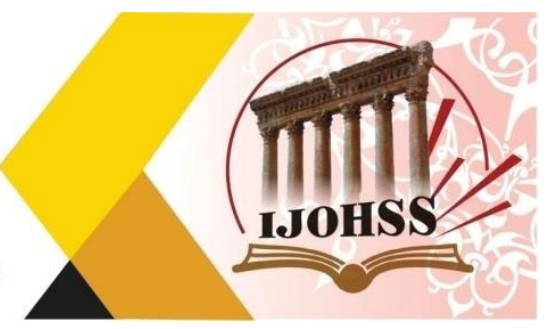

أيدت نسبة 75\% أنه من أهم مبادرات المشاركة العالمية تميز أكاديمية الملكة رانيا في تعليم اللغة العربية في

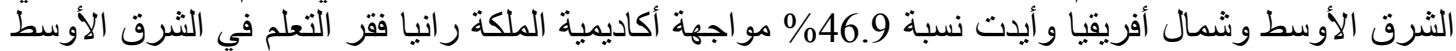
وشمال أفريقيا من خلال جهود المنصات الرات الرقمية.

الخاتمة

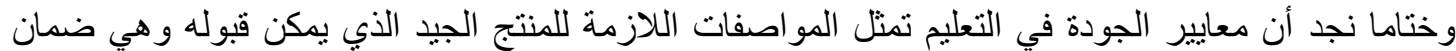

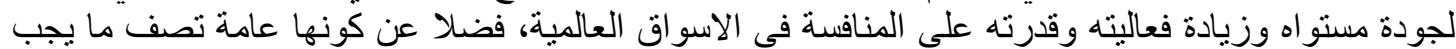

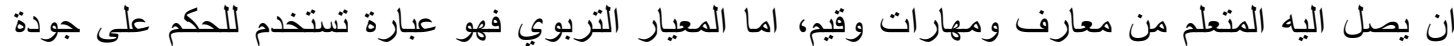

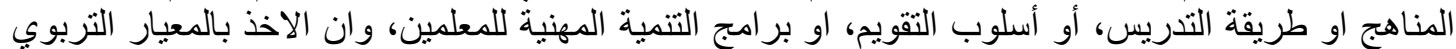

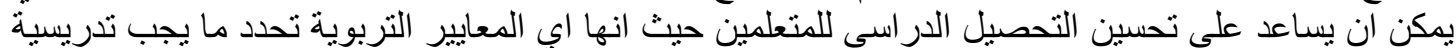

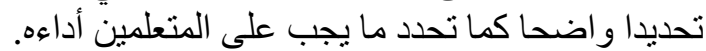

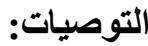

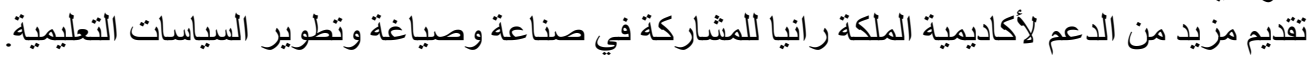

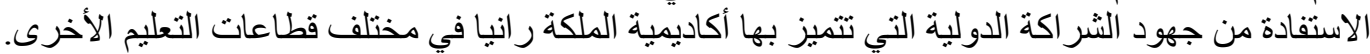
فتح المجال للتمويل الوطني الغير حكومي للمساهمة في اتساع بر امج وجهود أكاديمية الملكة رانيا.

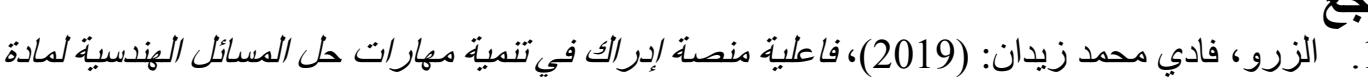
الرياضيات للدى طلبة الصف السابع الأساسي، رسالة ماجستير، كلية العلوم التربوية، جامعة الثرق الثرق

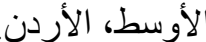
2. أبو ربيع، ابتسام أحمد طه: (2015)، مستوى إدراك مديري الددارس الأساسية الخاصة لأهيبة

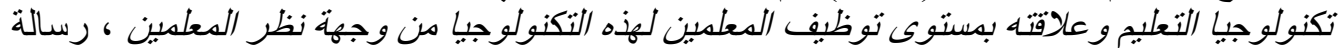

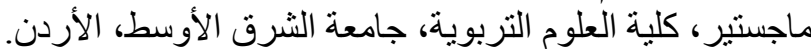

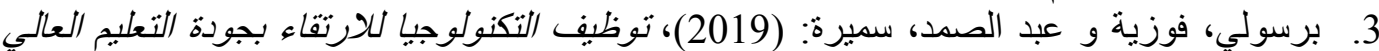

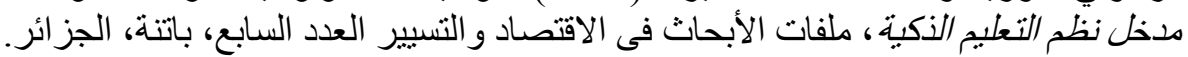

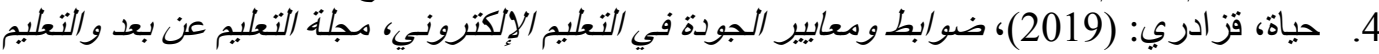

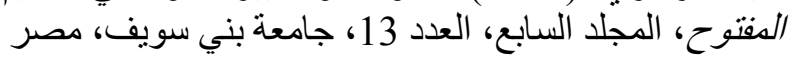

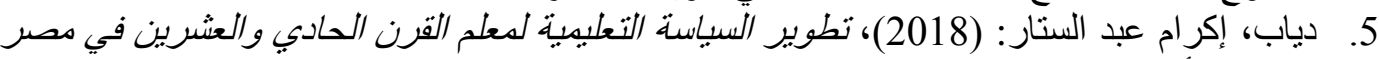
في ضوء أفضل المعارسات العالمبة، مجلة الإدارة التربوية، كلية التربية النوعية، جامعة الزفازيق،

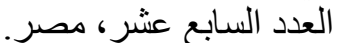
عبد اللطيف، سلامة حسنى عبد الرحيم: (2019)، تصور مقترح لتطوبير برامج التندريب لدعلمي التعلبم الثانوي الفني الصناعي بعصر على ضوء خبرة ألمانيا، رسالة ماجستير في التربية تخصص لتصن سياسات التعليم.

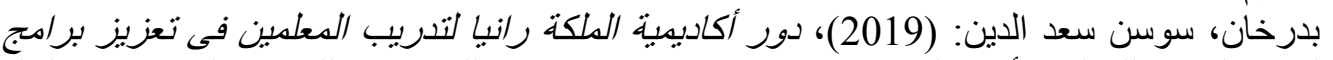

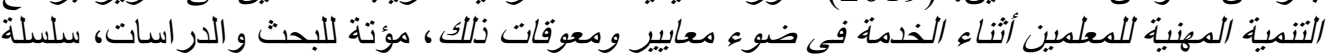
.7 العلوم الإنسانية والاجتماعية، المجلد 34، العندئ العدد الثاني

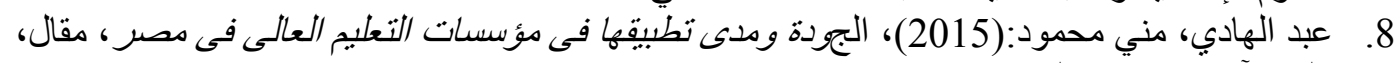
كلبة الآداب، جامعة القاهرة، مصرد. شلهل، محمد فتح الرحمن: (2016) ، استخدام وسائل الصور في تعليم مهارة الكتابة الصف العشر

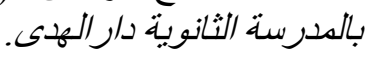
10. عاثور، حذام: (2014): تقنيات المعلومات والإتصالات في التعلبم والتندريب، المجلة الدولية للاتصالات الجمعية العربية للحاسبات عدد خاص، جامعة فلسطين الأهلية، فلسطين. 


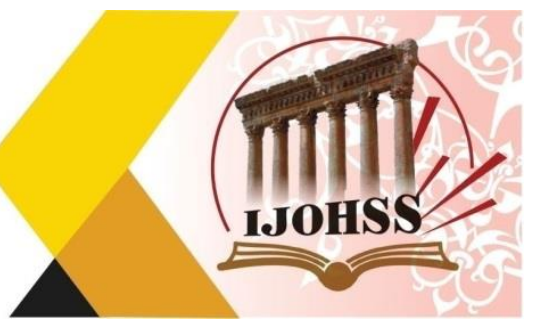

11. دياب، إكرام عبد الستار محمد: (2019) تطوبير السياسة التعليبية لمعلم القرن الحادي والعشربي، كلية

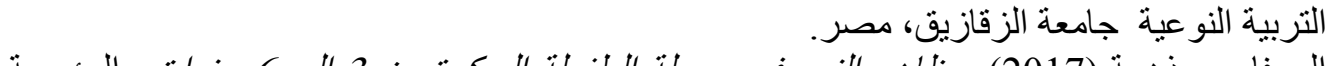

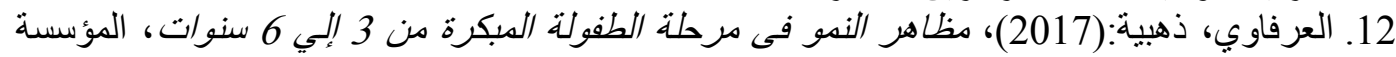

العربية للناستشار ات العبية: العبية وتنمية الموارد البشرية.

13. Agnihotri, Anil Kumar:(2017), quality in primary and secondary education, anil kumar agnihotri (4878-4884).

14. Bogatova, Marina: (2017), improving recruitment, selection and retention of employees' case, south eastern Finland, university applied science

15. https://www.unicef.org/education/early-childhood-education

16. https://en.unesco.org/sites/default/files/policy-breif-distance-learning-f-.

17. https://reliefweb.int/sites/reliefweb.int/files/resources/fostering_a_culture_of_resp onsibility_and_accountability.a.compressed.pdf.

18. https://qrta.edu.jo/

19. https://sustainabledevelopment.un.org/content/documents/20233SDGs_Arabic_Re port_972018_FINAL.pdf

20. https://www.ilo.org/global/about-the-ilo/newsroom/statements-and-

speeches/WCMS_311133/lang--ar/index.htm

21. https://kingabdullah.jo/ar/page/vision/\%D8\%A7\%D9\%84\%D8\%AA\%D9\%86\%D

9\%85\%D9\%8A\%D8\%A9 